\title{
QUEEN'S
UNIVERSITY
BELFAST
}

\section{Interventions to improve psychosocial well-being in female brca- mutation carriers following risk-reducing surgery}

Jeffers, L., Reid, J., Fitzsimons, D., Morrison, P. J., \& Dempster, M. (2019). Interventions to improve psychosocial well-being in female brca-mutation carriers following risk-reducing surgery. Cochrane Database of Systematic Reviews, 2019(10), [CD012894]. https://doi.org/10.1002/14651858.CD012894.pub2

Published in:

Cochrane Database of Systematic Reviews

Document Version:

Publisher's PDF, also known as Version of record

Queen's University Belfast - Research Portal:

Link to publication record in Queen's University Belfast Research Portal

Publisher rights

Copyright 2019 Cochrane Collaboration. This work is made available online in accordance with the publisher's policies. Please refer to any applicable terms of use of the publisher.

\section{General rights}

Copyright for the publications made accessible via the Queen's University Belfast Research Portal is retained by the author(s) and / or other copyright owners and it is a condition of accessing these publications that users recognise and abide by the legal requirements associated with these rights.

Take down policy

The Research Portal is Queen's institutional repository that provides access to Queen's research output. Every effort has been made to ensure that content in the Research Portal does not infringe any person's rights, or applicable UK laws. If you discover content in the Research Portal that you believe breaches copyright or violates any law, please contact openaccess@qub.ac.uk. 
Cochrane Database of Systematic Reviews

\section{Interventions to improve psychosocial well-being in female BRCA- mutation carriers following risk-reducing surgery (Review)}

Jeffers L, Reid J, Fitzsimons D, Morrison PJ, Dempster M

Jeffers L, Reid J, Fitzsimons D, Morrison PJ, Dempster M.

Interventions to improve psychosocial well-being in female BRCA-mutation carriers following risk-reducing surgery.

Cochrane Database of Systematic Reviews 2019, Issue 10. Art. No.: CD012894.

DOI: 10.1002/14651858.CD012894.pub2.

www.cochranelibrary.com 
TABLE OF CONTENTS

HEADER 1

ABSTRACT

PLAIN LANGUAGE SUMMARY

SUMMARY OF FINDINGS

BACKGROUND

OBJECTIVES

METHODS

Figure 1.

RESULTS

Figure 2.

DISCUSSION

AUTHORS' CONCLUSIONS

ACKNOWLEDGEMENTS

REFERENCES

CHARACTERISTICS OF STUDIES

ADDITIONAL TABLES

APPENDICES

CONTRIBUTIONS OF AUTHORS

DECLARATIONS OF INTEREST

SOURCES OF SUPPORT

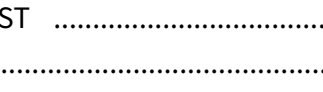

DIFFERENCES BETWEEN PROTOCOL AND REVIEW

1

2

4

7

9

9

11

14

16

17

18

18

19

25

29

35

43

43

43

43 
[Intervention Review]

\section{Interventions to improve psychosocial well-being in female BRCA- mutation carriers following risk-reducing surgery}

Lisa Jeffers $^{1}$, Joanne Reid², Donna Fitzsimons², Patrick J Morrison¹,3, Martin Dempster ${ }^{4}$

1 Medical Genetics, Regional Medical Genetics Centre, Belfast, UK. 2School of Nursing and Midwifery, Queen's University Belfast, Belfast, UK. ${ }^{3}$ Centre for Cancer Research and Cell Biology, Queen's University Belfast, Belfast, UK. ${ }^{4}$ School of Psychology, Queen's University Belfast, Belfast, UK

Contact address: Lisa Jeffers, Medical Genetics, Regional Medical Genetics Centre, Belfast Health and Social Care Trust, Lisburn Road, Belfast, BT9 7AB, UK. ljeffers14@yahoo.com, lisa.jeffers@belfasttrust.hscni.net.

Editorial group: Cochrane Gynaecological, Neuro-oncology and Orphan Cancer Group

Publication status and date: New, published in Issue 10, 2019.

Citation: Jeffers L, Reid J, Fitzsimons D, Morrison PJ, Dempster M. Interventions to improve psychosocial well-being in female BRCAmutation carriers following risk-reducing surgery. Cochrane Database of Systematic Reviews 2019, Issue 10. Art. No.: CD012894. DOI: 10.1002/14651858.CD012894.pub2.

Copyright ( 2019 The Cochrane Collaboration. Published by John Wiley \& Sons, Ltd.

\section{A B S T R A C T}

\section{Background}

Women who carry a pathogenic mutation in either a BRCA1 DNA repair associated or BRCA2 DNA repair associated (BRCA1 or BRCA2) gene have a high lifetime risk of developing breast and tubo-ovarian cancer. To manage this risk women may choose to undergo risk-reducing surgery to remove breast tissue, ovaries, and fallopian tubes. Surgery should increase survival, but can impact women's lives adversely at the psychological and psychosexual levels. Interventions to facilitate psychological adjustment and improve quality of life post riskreducing surgery are needed.

\section{Objectives}

To examine psychosocial interventions in female BRCA carriers who have undergone risk-reducing surgery and to evaluate the effectiveness of such interventions on psychological adjustment and quality of life.

\section{Search methods}

We searched the Cochrane Central Register of Controlled Trials (CENTRAL) in the Cochrane Library, MEDLINE and Embase via Ovid, CINAHL, PsycINFO, Web of Science up to April 2019 and Scopus up to January 2018. We also handsearched abstracts of scientific meetings and other relevant publications.

\section{Selection criteria}

We included randomised controlled trials (RCT), non-randomised studies (NRS), prospective and retrospective cohort studies and interventional studies using baseline and postintervention analyses in female BRCA carriers who have undergone risk-reducing surgery.

\section{Data collection and analysis}

Two review authors independently assessed eligibility studies for inclusion in the review. We used standard methodological procedures expected by Cochrane.

\section{Main results}

We screened 4956 records from the searches, selecting 34 unique studies for full-text scrutiny, of which two met the inclusion criteria: one RCT and one NRS. The included studies assessed 113 female BRCA carriers who had risk-reducing surgery, but there was attrition, and outcome data were not available for all participants at final study assessments. We assessed the RCT as at a high risk of bias whilst the NRS 
did not have a control group. Our GRADE assessment of the studies was very low-certainty due to the paucity of data and methodological shortcomings of the studies. The primary outcome of quality of life was only measured in the RCT and that was specific to the menopause. Both studies reported on psychological distress and sexual function. Neither study measured body image, perhaps because this is most often associated with risk-reducing mastectomy rather than oophorectomy.

The RCT (66 participants recruited with 48 followed to 12 months) assessed the short- and long-term effects of an eight-week mindfulness-based stress reduction (MBSR) training programme on quality of life, sexual functioning, and sexual distress in female BRCA carriers $(n=34)$ in a specialised family cancer clinic in the Netherlands compared to female BRCA carriers $(n=32)$ who received usual care. Measurements on the Menopause-Specific Quality of Life Questionnaire (MENQOL) showed some improvement at 3 and 12 months compared to the usual care group. At 3 months the mean MENQOL scores were 3.5 (95\% confidence interval $(\mathrm{Cl}) 3.0$ to 3.9$)$ and 3.8 (95\% $\mathrm{Cl} 3.3$ to 4.2) for the MBSR and usual care groups respectively, whilst at 12 months the corresponding values were $3.6(95 \% \mathrm{Cl} 3.1$ to 4.0$)$ and 3.9 (95\% Cl 3.5 to 4.4) (1 study; 48 participants followed up at 12 months). However, these results should be interpreted with caution due to the very low-certainty of the evidence, where a lower score is better. Other outcome measures on the Female Sexual Function Index and the Female Sexual Distress Scale showed no significant differences between the two groups. Our GRADE assessment of the evidence was very low-certainty due to the lack of blinding of participants and personnel, attrition bias and self-selection (as only one-third of eligible women chose to participate in the study) and serious imprecision due to the small sample size and wide $95 \% \mathrm{Cl}$.

The NRS comprised 37 female BRCA carriers selected from three Boston-area hospitals who had undergone a novel sexual health intervention following risk-reducing salpingo-oophorectomy (RRSO) without a history of tubo-ovarian cancer. The intervention consisted of targeted sexual-health education, body awareness and relaxation training, and mindfulness-based cognitive therapy strategies, followed by two sessions of tailored telephone counselling. This was a single-arm study without a control group. Our GRADE assessment of the evidence was very low-certainty, and as there was no comparison group in the included study, we could not estimate a relative effect. The study reported change in psychosexual adjustment from baseline to postintervention (median 2.3 months) using measures of Female Sexual Function Index $(n=34)$, which yielded change with a mean of 3.91, standard deviation (SD) 9.12, $P=0.018$ (1 study, 34 participants; very low-certainty evidence). The Brief Symptom Inventory, Global Severity Index yielded a mean change of 3.92, SD 5.94, P $<0.001$. The Sexual Self-Efficacy Scale yielded change with a mean of 12.14, SD 20.56, P $<0.001$. The Sexual Knowledge Scale reported mean change of 1.08 , SD 1.50, $P<0.001(n=36)$. Participant satisfaction was measured by questionnaire, and $100 \%$ participants reported that they enjoyed taking part in the psychoeducation group and felt "certain" or "very certain" that they had learned new skills to help them cope with the sexual side effects of RRSO.

\section{Authors' conclusions}

The effect of psychosocial interventions on quality of life and emotional well-being in female BRCA carriers who undergo risk-reducing surgery is uncertain given the very low methodological quality in the two studies included in the review. The absence of such interventions highlights the need for partnership between researchers and clinicians in this specific area to take forward the patient-reported outcomes and develop interventions to address the psychosocial issues related to risk-reducing surgery in female BRCA carriers, particularly in this new era of genomics, where testing may become more mainstream and many more women are identified as gene carriers.

\section{PLAIN LANGUAGE SUMMARY}

\section{Interventions to improve psychosocial well-being in women with a BRCA mutation following risk-reducing surgery}

\section{Background}

Women who test positive for a fault (mutation) on one of the BRCA genes (BRCA1 DNA repair associated or BRCA2 DNA repair associated (BRCA1 or BRCA2)) are more at risk of developing breast and tubo-ovarian cancer (cancer of the fallopian tubes or ovaries). A significant number of female BRCA carriers will choose to have surgery to remove their breast tissue and fallopian tubes and ovaries in order to reduce their risk of developing breast cancer and tubo-ovarian cancer. This type of surgery can be life-changing, and women may experience negative physical and emotional changes as a result. These changes can affect the function and appearance of their bodies, which in turn can have a negative psychological effect on women and their relationships.

\section{Review question}

The aim of this review was to learn if interventions can help with the social and psychological effects of physical and emotional changes in women who have had risk-reducing surgery.

\section{Main findings}

We found two studies that examined a psychosocial intervention for women who had undergone removal of their fallopian tubes and ovaries to reduce their risk of tubo-ovarian cancer.

One randomised controlled trial (a study in which participants are assigned to one of two or more treatment groups using a random method) assessed a mindfulness-based stress reduction training programme for menopausal symptoms after risk-reducing surgery. Whilst there was improvement in the menopause-specific quality of life scores in the short and the long term for women with menopausal symptoms, the intervention was not associated an with improvement in sexual functioning or distress. 
Women who participated in a non-randomised study all received the study intervention and scored themselves on certain items related to psychosexual functioning and psychological adjustment before and after the intervention (targeted sexual-health education, body awareness and relaxation training, and mindfulness-based cognitive therapy strategies). They also received a group psychoeducation session and telephone counselling. The outcomes were based on the differences between the before and after scores. All women recruited to the study were at risk of tubo-ovarian cancer based on having a harmful or faulty BRCA gene, but there was no personal history of tubo-ovarian cancer in the group studied.

No studies reported on social and psychological interventions following risk-reducing surgery to have breast tissue removed in BRCA carriers.

\section{Quality of the evidence}

The certainty (quality) of the evidence ranged from moderate to very low, with only one randomised controlled trial and one non-randomised study that had no comparator included in the review. Both studies involved small numbers of women.

\section{Conclusions}

The limited, moderate- to very low-certainty evidence meant that we were unable to draw any conclusions regarding psychosocial interventions following risk-reducing surgery in female BRCA carriers on improvement in quality of life and psychological (emotional) adjustment. Further research is required to determine how best to support women who choose to have risk-reducing surgery. 


\section{SUMMARY OF FINDINGS}

Summary of findings for the main comparison. Mindfulness-based stress reduction training versus usual care for female BRCA carriers post-riskreducing surgery

Mindfulness-based stress reduction training versus usual care for female BRCAcarriers post-risk-reducing surgery

Patient or population: female BRCA carriers post-risk-reducing surgery

Setting: a specialised family cancer clinic in Groningen, the Netherlands

Intervention: mindfulness-based stress reduction training

Comparison: usual care

\begin{tabular}{|c|c|c|c|c|c|}
\hline \multirow[t]{2}{*}{ Outcomes } & \multicolumn{2}{|c|}{ Anticipated absolute effects ${ }^{\star}(95 \% \mathrm{Cl})$} & \multirow{2}{*}{$\begin{array}{l}\text { Relative ef- } \\
\text { fect } \\
(95 \% \mathrm{CI})\end{array}$} & \multirow{2}{*}{$\begin{array}{l}\text { № of partici- } \\
\text { pants } \\
\text { (studies) }\end{array}$} & \multirow{2}{*}{$\begin{array}{l}\text { Certainty of } \\
\text { the evidence } \\
\text { (GRADE) }\end{array}$} \\
\hline & Risk with usual care & $\begin{array}{l}\text { Risk with mindfulness-based stress } \\
\text { reduction training }\end{array}$ & & & \\
\hline $\begin{array}{l}\text { Menopause-specific quality of life (quality of } \\
\text { life) } \\
\text { assessed with: MENQOL } \\
\text { follow-up: mean } 12 \text { months }\end{array}$ & $\begin{array}{l}\text { The mean menopause-specif- } \\
\text { ic quality of life was } 3.9 \text {. }\end{array}$ & $\begin{array}{l}\text { MD - } 0.3 \text { lower } \\
\text { (- } 0.94 \text { lower to } 0.34 \text { higher) }\end{array}$ & - & $\begin{array}{l}48 \\
(1 \mathrm{RCT})\end{array}$ & $\begin{array}{l}\oplus \odot \odot \ominus \\
\text { VERY LOW } 12\end{array}$ \\
\hline $\begin{array}{l}\text { Sexual function (sexual function) } \\
\text { assessed with: Female Sexual Function In- } \\
\text { dex } \\
\text { follow-up: mean } 12 \text { months }\end{array}$ & $\begin{array}{l}\text { The mean sexual function was } \\
\text { 16.3. }\end{array}$ & $\begin{array}{l}\text { MD } 0.5 \text { higher } \\
\text { (- } 4.14 \text { lower to } 5.14 \text { higher })\end{array}$ & - & $\begin{array}{l}48 \\
(1 \mathrm{RCT})\end{array}$ & $\begin{array}{l}\oplus \Theta \Theta \odot \\
\text { VERY LOW } 12\end{array}$ \\
\hline $\begin{array}{l}\text { Sexual distress (sexual distress) } \\
\text { assessed with: Female Sexual Distress Scale } \\
\text { follow-up: mean } 12 \text { months }\end{array}$ & $\begin{array}{l}\text { The mean sexual distress was } \\
\text { 12.4. }\end{array}$ & $\begin{array}{l}\text { MD } 5.2 \text { higher } \\
\text { (- } 1.67 \text { lower to } 12.07 \text { higher) }\end{array}$ & - & $\begin{array}{l}48 \\
(1 \mathrm{RCT})\end{array}$ & $\begin{array}{l}\oplus \Theta \Theta \odot \\
\text { VERY LOW } 12\end{array}$ \\
\hline $\begin{array}{l}\text { Psychosocial (psychosocial) } \\
\text { assessed with: MENQOL } \\
\text { follow-up: mean } 12 \text { months }\end{array}$ & $\begin{array}{l}\text { The mean psychosocial was } \\
\text { 3.8. }\end{array}$ & $\begin{array}{l}\text { MD - } 0.1 \text { lower } \\
\text { (- } 0.91 \text { lower to } 0.71 \text { higher) }\end{array}$ & - & $\begin{array}{l}48 \\
(1 \mathrm{RCT})\end{array}$ & $\begin{array}{l}\oplus \odot \Theta \odot \\
\text { VERY LOW } 12\end{array}$ \\
\hline $\begin{array}{l}\text { Physical symptoms (physical) } \\
\text { assessed with: MENQOL } \\
\text { follow-up: mean } 12 \text { months }\end{array}$ & $\begin{array}{l}\text { The mean physical symptoms } \\
\text { was 3.8. }\end{array}$ & $\begin{array}{l}\text { MD - } 0.6 \text { lower } \\
\text { (- } 1.23 \text { lower to } 0.04 \text { higher })\end{array}$ & - & $\begin{array}{l}48 \\
(1 \mathrm{RCT})\end{array}$ & $\begin{array}{l}\oplus \Theta \Theta \Theta \\
\text { VERY LOW } 12\end{array}$ \\
\hline
\end{tabular}




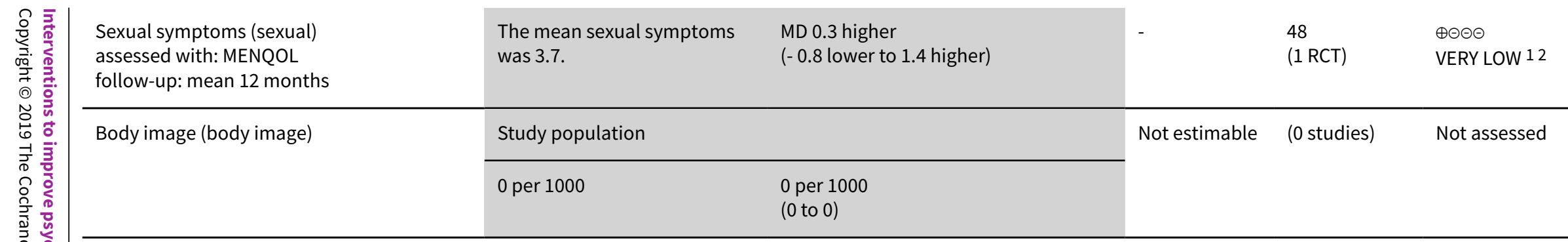

${ }^{\star}$ The risk in the intervention group (and its $95 \%$ confidence interval) is based on the assumed risk in the comparison group and the relative effect of the intervention (and its $95 \% \mathrm{Cl}$ ).

CI: confidence interval; MD: mean difference; MENQOL: Menopause-Specific Quality of Life questionnaire; RCT: randomised controlled trial

\section{GRADE Working Group grades of evidence}

High-certainty: We are very confident that the true effect lies close to that of the estimate of the effect.

Moderate-certainty: We are moderately confident in the effect estimate: the true effect is likely to be close to the estimate of the effect, but there is a possibility that it is substantially different.

Low-certainty: Our confidence in the effect estimate is limited: the true effect may be substantially different from the estimate of the effect.

Very low-certainty: We have very little confidence in the effect estimate: the true effect is likely to be substantially different from the estimate of effect.

1Serious imprecision due to small sample size and wide $95 \% \mathrm{Cl}$. Downgraded one level.

2 Very serious risk of bias due to lack of blinding of participants and personnel, attrition bias, and self-selection bias (as only one-third of eligible women chose to participate in the study). Downgraded two levels.

Summary of findings 2. Psychosocial intervention to improve sexual health versus no intervention for adult women, 18 years of age or older, who tested positive for a pathogenic mutation in BRCA1 or BRCA2 and who had had risk-reducing surgery

Psychosocial intervention to improve sexual health versus no intervention for adult women, 18 years of age or older, who tested positive for a pathogenic mutation in BRCA1 or BRCA2 and who had had risk-reducing surgery

Patient or population: adult women, 18 years of age or older, who tested positive for a pathogenic mutation in BRCA1 or BRCA2 and who had had risk-reducing surgery Setting: outpatient clinics in Boston, USA

Intervention: psychosocial intervention to improve sexual health

Comparison: no intervention

\begin{tabular}{|c|c|c|c|}
\hline Outcomes & Impact & $\begin{array}{l}\text { № of partici- } \\
\text { pants } \\
\text { (studies) }\end{array}$ & $\begin{array}{l}\text { Certainty of the } \\
\text { evidence } \\
\text { (GRADE) }\end{array}$ \\
\hline Quality of life & Not assessed by this study & 0 & Not estimable \\
\hline
\end{tabular}




\begin{tabular}{|c|c|c|c|c|}
\hline 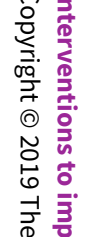 & $\begin{array}{l}\text { Sexual function } \\
\text { assessed with: rating scales, psy- } \\
\text { choeducational group session, tele- } \\
\text { phone counselling } \\
\text { follow-up: mean } 2 \text { months }\end{array}$ & $\begin{array}{l}\text { Women showed significant improvement in sexual function }(M=3.91) \text {. Magnitude of } \\
\text { change between baseline and postintervention varied, with moderate to moderately } \\
\text { large effect sizes observed on the desire }(M=0.44) \text { and arousal }(M=0.98) \text { subscales of the } \\
\text { FSFI. FSFI total score, satisfaction }(M=0.53) \text {, and pain }(M=0.93) \text { subscales showed small } \\
\text { to moderate effect sizes. Improvements in lubrication }(M=0.58) \text { and orgasm ( } M=0.73) \\
\text { scales were observed but were not statistically significant. }\end{array}$ & $\begin{array}{l}34 \\
\text { (1 observational } \\
\text { study) }\end{array}$ & $\begin{array}{l}\oplus \ominus \ominus \ominus \\
\text { VERY LOW12 }\end{array}$ \\
\hline & Body image & Not assessed by this study & 0 & Not estimable \\
\hline 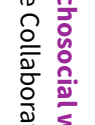 & $\begin{array}{l}\text { Sexual self-efficacy scale } \\
\text { assessed with: rating scale } \\
\text { follow-up: mean } 2 \text { months }\end{array}$ & $\begin{array}{l}\text { Women rated their perceived certainty or confidence to address sexual side effects of } \\
\text { RRSO. Moderate to moderately large change effect was shown on this scale between } \\
\text { baseline and postintervention }(M=12.14)(P<0.001) \text {. }\end{array}$ & $\begin{array}{l}37 \\
\text { (1 observational } \\
\text { study) }\end{array}$ & $\begin{array}{l}\oplus \odot \Theta \odot \\
\text { VERY LOW } 12\end{array}$ \\
\hline 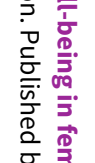 & $\begin{array}{l}\text { Sexual knowledge } \\
\text { assessed with: measured on a true/ } \\
\text { false } 10 \text {-item scale } \\
\text { follow-up: mean } 2 \text { months }\end{array}$ & $\begin{array}{l}\text { Women's perceived knowledge about sexual side effects of RRSO was significantly im- } \\
\text { proved from baseline to postintervention }(M=1.08)(P<0.001) \text {. }\end{array}$ & $\begin{array}{l}36 \\
\text { (1 observational } \\
\text { study) }\end{array}$ & $\begin{array}{l}\oplus \odot \Theta \odot \\
\text { VERY LOW } 12\end{array}$ \\
\hline 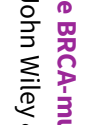 & $\begin{array}{l}\text { Participant satisfaction } \\
\text { assessed with: questionnaire } \\
\text { follow-up: mean } 2 \text { months }\end{array}$ & $\begin{array}{l}100 \% \text { of women reported that they enjoyed participating in the psychoeducation group } \\
\text { session and felt "certain" or "very certain" that they had learned new skills to help them } \\
\text { cope with the sexual side effects of RRSO. }\end{array}$ & $\begin{array}{l}37 \\
\text { (1 observational } \\
\text { study) }\end{array}$ & $\begin{array}{l}\oplus \odot \Theta \odot \\
\text { VERY LOW } 12\end{array}$ \\
\hline 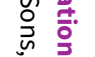 & \multicolumn{4}{|c|}{ FSFI: Female Sexual Function Index; RRSO: risk-reducing salpingo-oophorectomy } \\
\hline 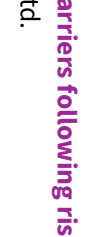 & \multicolumn{4}{|c|}{$\begin{array}{l}\text { GRADE Working Group grades of evidence } \\
\text { High-certainty: We are very confident that the true effect lies close to that of the estimate of the effect. } \\
\text { Moderate-certainty: We are moderately confident in the effect estimate: the true effect is likely to be close to the estimate of the effect, but there is a possibility that it is } \\
\text { substantially different. } \\
\text { Low-certainty: Our confidence in the effect estimate is limited: the true effect may be substantially different from the estimate of the effect. } \\
\text { Very low-certainty: We have very little confidence in the effect estimate: the true effect is likely to be substantially different from the estimate of effect. }\end{array}$} \\
\hline
\end{tabular}

${ }^{1}$ No control group. Downgraded two levels.

2Self-selection to study. Downgraded one level. 


\section{B A C K G R O U N D}

The familial breast cancer genes BRCA1 DNA repair associated and $B R C A 2 D N A$ repair associated (BRCA1 and BRCA2) have garnered attention since individuals of public interest have revealed their personal decisions to undergo risk-reducing surgery for breast or tuboovarian cancer, or both, because of a family history of these cancers and a positive gene status (Evans 2015). Raising the public profile of inherited breast and tubo-ovarian cancer has resulted in substantial increases in referrals to cancer genetics services throughout the UK (Evans 2015; Foster 2007; Rosenberg 2016; Watson 2004). This exposure, alongside factors that have increased availability of genetic testing such as Next Generation Sequencing (NGS) and updated National Institute for Health and Care Excellence (NICE) guidelines on genetic testing in families with hereditary breast and ovarian cancer (HBOC) (NICE 2013), has influenced the perception and uptake of genetic testing. In addition, the 100,000 Genome Project has started to deliver results in 2019 from sequencing the genomes of 85,000 individuals with rare disease or cancers and has the potential to identify many more BRCA mutations. This is currently the largest national sequencing project of its kind in the world (Genomics England 2019). Prior to genetic testing for BRCA genes, which remains the most powerful tool for determining which individuals within a family are at risk (Euhus 2015), genetic counselling is offered where trained genetic counsellors can facilitate testing in a number of ways including discussion of family history, possible test outcomes, implications of the genetic test result, and risk management options (Stan 2013). Current NICE guidance sets out the classification, care and management of familial breast cancer and related risks in people with a family history of breast cancer and defines those whose risk warrants a specialist genetic consultation (NICE 2013).

\section{Description of the condition}

Hereditary breast and ovarian cancer is a syndrome that increases the risk of developing breast and tubo-ovarian cancer. It is estimated that up to $10 \%$ of invasive breast cancers are inherited, most of which are associated with the BRCA1 and BRCA2 genes (King 2003). Up to $17 \%$ of women diagnosed with tubo-ovarian cancers have an inherited pathogenic BRCA mutation (McAlpine 2012). NHS England has reported that a BRCA gene mutation accounts for 1020 of the 6800 cases of tubo-ovarian cancer diagnosed annually in the UK (NHS England 2015). Women who carry a pathogenic BRCA mutation are considered to have a significantly increased cumulative lifetime risk of developing breast cancer ( $40 \%$ to $85 \%$ ) and risk of tubo-ovarian cancer (11\% to 65\%) (Antoniou 2003; den Heijer 2012; Ford 1998; King 2003), compared to women in the general population, where risk for breast and tubo-ovarian cancer is $12 \%$ and $1.3 \%$ respectively (Chen 2007). Whilst it is acknowledged that published estimates vary depending on study design, analyses, and populations studied (Hartmann 2016), multiple other factors such as age of diagnosis of cancer in the index family member, type of cancer, family history of cancer, and lifestyle factors contribute to this variation in risk (Mavaddat 2013). The Epidemiological Study of BRCA1 and BRCA2 mutation carriers (EMBRACE), one of the largest prospective studies, collaborating with 28 centres across the UK and Ireland, discriminated between the two BRCA genes. The estimated cumulative lifetime risks, up to 70 years of age, for women with a BRCA1 mutation are $60 \%$ risk of breast cancer, $59 \%$ for tubo-ovarian cancer, and $83 \%$ for a contralateral breast cancer; for women with a BRCA2 mutation risks were estimated as
$55 \%$ for breast cancer, $16.5 \%$ for ovarian cancer, and $62 \%$ for contralateral breast cancer (Mavaddat 2013).

Following confirmation of a pathogenic BRCA mutation, women are faced with difficult choices of how best to manage their risk of developing breast or tubo-ovarian cancer. Options to consider are: enhanced surveillance with magnetic resonance imaging (MRI), mammogram, and CA125 blood test, and a transvaginal ultrasound scan of the ovaries and fallopian tubes; risk-reducing surgery to remove their breast tissue and/or ovaries and fallopian tubes; chemoprevention; and lifestyle interventions. A recent Cochrane Review protocol highlights the need for international guidelines in BRCA testing in women with tubo-ovarian cancer and other cancers to facilitate consistent screening practices (Eleje 2016). The UK Familial Ovarian Cancer Screening Study (UK FOCSS) recently published data on screening in women who are at high risk for tubo-ovarian cancer. It concluded that screening should not be viewed as an alternative to surgery, but it does seem to offer a better chance of avoiding a diagnosis of advanced incompletely resectable tubo-ovarian cancer in the interim (Rosenthal 2017). Serous tubal intraepithelial carcinoma (STIC) is considered to be a precursor lesion of highgrade serous ovarian cancer (HGSOC), and studies in germline BRCA carriers who have undergone bilateral salpingo-oophorectomy (BSO) as a risk-reducing procedure have reported that STIC lesions were present within the fallopian tube in $0.6 \%$ to $7 \%$ of cases (Crum 2013). A systematic review of the association of STIC and HGSOC (Chen 2017), whilst reporting on the variability and the significant methodological inconsistencies resulting in a wide range of reported incidence of concurrent STIC and HGSOC, did identify findings that strengthen the hypothesis that HGSOC originates from the fallopian tube. Based on growing evidence for this hypothesis, the use of prophylactic salpingectomy (without oophorectomy) is increasing, but there have yet to be formal studies to demonstrate the effectiveness and safety of such an approach (Chay 2016), whilst Ayres 2017 challenged the recommendation of this technique and urged caution using this technique alone for high-risk patients. Recently, the PROTECTOR study has been set up in the UK to offer a two-stage process for risk-reducing salpingo-oophorectomy (RRSO). The study aims to assess the impact on women of the new two-step option to prevent ovarian cancer and will assess women's views and the impact of this approach to prevent ovarian cancer on sexual function, hormone levels, quality of life, and overall satisfaction.

Given the high risks of breast and tubo-ovarian cancer associated with the BRCA genes, many women choose to undergo risk-reducing mastectomy or RRSO, or both, in order to maximise survival (Jeffers 2014). It has been reported that $18 \%$ to $40 \%$ of women with a BRCA gene mutation will opt for risk-reducing mastectomy (Euhus 2015), with the higher percentage reported in the UK (Euhus 2015; Gopie 2013). Approximately $60 \%$ of women between the ages of 35 and 70 years who are BRCA carriers will elect to undergo RRSO (Finch 2013). Prospective studies report a 93\% reduction in breast cancer risk for women who undergo risk-reducing mastectomy (De Felice 2015). Similarly, RRSO may reduce the risk of tuboovarian cancer by $85 \%$ to $90 \%$ and breast cancer risk by $40 \%$ to $70 \%$ in women who are BRCA carriers (ACOG 2009). Whilst such surgical interventions have demonstrated increased overall survival for this population, surgery is life-changing and can impact women adversely at the psychological, psychosexual, and emotional levels (Hartmann 2016; Stan 2013). In general, women regard risk-reducing surgery as a positive experience and have a sense of relief 
at the substantial cancer risk reduction and improvement in survival (Metcalfe 2004). However, studies have shown that despite this positive experience, women are faced with unexpected physical changes that affect the function and appearance of their bodies. These changes can have a negative impact on sexuality and relationships (Gahm 2013; Gopie 2013; Hallowell 2012). The focus of this Cochrane Review is the effectiveness of interventions on psychosocial outcomes, and survival will not be part of the scope.

\section{Description of the intervention}

Prior to genetic testing, women at risk of cancer are provided with genetic counselling by trained genetic counsellors or consultant geneticists, as directed by NICE guidance 164 (NICE 2013). As an activity, genetic counselling is "the process of helping people understand and adapt to the medical, psychological and familial implications of the genetic contributions to disease. The process includes interpretation, risk assessment, education and counselling" (Resta 2006). Genetic counselling is not synonymous with therapeutic counselling. The role of the genetic counsellor, according to Skirton 2010, is specifically as follows.

- To identify the needs of the individual or family and use an empathic client-centred approach in the provision of genetic counselling.

- To collect, select, interpret, and analyse information (including family and medical history, pedigree, laboratory results, and literature) relevant to the delivery of genetic counselling for individuals or families.

- To help people understand and adapt to the medical, psychological, social, and familial implications of genetic contributions to disease.

- To assess the chance of occurrence or recurrence.

- To provide education about inheritance, testing, management, prevention, resources, and research to relevant individuals or families.

- To promote informed choices and psychological adaption to the condition or risk of the condition.

- To apply expert knowledge to facilitate the individual or family to access the appropriate healthcare resources, including a medical diagnosis and resources for management of the condition.

Women with a diagnosis of cancer may experience a different pathway due to the recent 'mainstreaming' of cancer genetics in some areas in the UK and beyond (genetic testing outside of clinical genetics services). Women who have a diagnosis of cancer may access genetic testing at the time of diagnosis, with the pre-test counselling provided by oncologists or surgeons. If a mutation is identified, these women can be referred to genetic services for further information and genetic counselling. Individuals who test positive for a BRCA mutation are not routinely followed up by the genetics service after their result disclosure consultation, but are referred on for screening and risk-reducing consultations with surgeons.

The extent of need for psychosocial support in women who are BRCA carriers and who have undergone risk-reducing surgery has not been wholly quantified. However, retrospective and prospective studies have highlighted women's concerns and experiences (Brandberg 2008; den Heijer 2012; Gahm 2010; McGaughey 2006; Metcalfe 2004; van Oostrom 2003), with significant numbers of women reporting some adverse experience. Studies have report- ed on long-term follow-up of BRCA carriers who had risk-reducing surgery (Bai 2019; Hall 2019). Studies have found that approximately one-third of women felt less feminine, with reported changes in sexual attractiveness (55\%), feeling less physically attractive (53\%), and self-consciousness about appearance (53\%) (Hopwood 2000). Other concerns were related to surgical complications for which women received further psychiatric intervention (Hopwood 2000). Women without a diagnosis of cancer who underwent risk-reducing mastectomy felt embarrassed about their naked body (21\%), were not satisfied with the appearance of reconstructed breasts (29\%), but reported significant reduction in cancer-specific distress (Gopie 2013). Women who are BRCA gene carriers and have undergone oophorectomy have been shown to experience worsening menopausal symptoms and a decline in sexual functioning, particularly those women who had surgery before their natural menopause (Hall 2019).

This Cochrane Review focused on psychological, psychosexual, and psychoeducational interventions provided to support female BRCA carriers after risk-reducing surgery, and the effectiveness of such interventions on quality of life and the psychological consequences of risk-reducing surgical intervention. Whilst there is no universal definition of quality of life, it is used to describe general health status (Aaronson 1998; Barofsky 2012). Interventions for this review adhered to a previous Cochrane Review's definition of a psychosocial intervention as non-pharmacological, involving an interpersonal relationship between an individual or group of individuals, and one or more trained (usually professional) helpers (Galway 2012).

\section{How the intervention might work}

Genetic testing and the resulting medical decisions around risk reduction lead to a unique set of emotional, physical, and sexual issues for women who are BRCA carriers (Matloff 2009). Risk-reducing salpingo-oophorectomy results in surgically induced menopause, which is related to significantly compromised sexual function (Bober 2015; Finch 2011; Robson 2003), for which there is little effective treatment. Studies have shown that psychosocial interventions have improved women's sexual difficulties (Bober 2015). Improvements in overall sexual functioning, including desire, arousal, satisfaction, and pain, have been demonstrated using interventions that integrate elements of cognitive behavioural therapy with sexual-health education and mindfulness meditation (Bober 2015). Similarly, mindfulness-based interventions in people with breast cancer have shown improvements in quality of life and stress reduction (Lengacher 2009).

\section{Why it is important to do this review}

Whilst the literature recognises that risk-reducing procedures have a significant impact at a psychosocial level and can affect quality of life, both at an individual level and that of the family (Brotto 2012; Finch 2013; Gopie 2013; Hallowell 2012; Jeffers 2014; Stan 2013), psychosocial interventions in this population have yet to be systematically reviewed. Previous systematic reviews and metaanalyses have assessed the efficacy of psychological interventions in people attending sessions for sexual dysfunction (Frühauf 2013). There has been an informative literature review on the influence of medical choices on quality of life in unaffected BRCA carriers (Harmsen 2015b). Given the developments in genetic testing and the increase in availability and uptake of testing, coupled with improved surgical techniques such as breast reconstruction, more 
women are choosing to undergo prophylactic bilateral mastectomy: a $12 \%$ annual increase over the last decade has been reported in the USA (Euhus 2015). Long-term follow-up studies on the impact of risk-reducing mastectomy have shown that women had ongoing difficulties with body image up to two to nine years after surgery (den Heijer 2012; Unukovych 2012). Studies have shown that sexual side effects are the most commonly cited areas of concern post-RRSO for women who are BRCA gene carriers, yet $60 \%$ of the most common symptoms women experienced postsurgery had not been discussed before surgery (Campfield Bonadies 2011). There are numerous studies measuring self-report psychological and quality of life outcomes following risk-reducing surgery (Alamouti 2015; Altschuler 2008; Fang 2009; Hall 2019; Isern 2008; Lodder 2002; Modaffari 2019), but there is a need to use these research findings to develop interventions for use in clinical practice in order to improve the psychosocial well-being in this population. Women need to be provided with information and supportive interventions to ensure they have the best psychological outcomes following their decision to undergo risk-reducing surgery. It is noted that the pre-test counselling and decision aids may impact the need for post-test counselling and interventions, but this is not within the scope of this review. This review identified the psychosocial care and management of and its impact on this cohort of women postrisk-reducing surgery.

\section{O B J E C T IVES}

To examine psychosocial interventions in female BRCA carriers who have undergone risk-reducing surgery, and to evaluate the effectiveness of such interventions on psychological adjustment and quality of life.

\section{METHODS}

\section{Criteria for considering studies for this review}

\section{Types of studies}

- Randomised controlled trials (RCTs)

- Non-randomised studies (NRS), prospective and retrospective cohort studies

- Interventional studies

\section{Types of participants}

Women, 18 years or older, who tested positive for a pathogenic mutation in BRCA1 or BRCA2, or both. We included women who had had risk-reducing mastectomy or RRSO, or both. We included women with or without a diagnosis of breast or tubo-ovarian cancer.

\section{Types of interventions}

We sought to include the following:

- psychological interventions such as cognitive behavioural therapy, behavioural therapy, mindfulness-based stress reduction (MBSR);

- psychoeducational, to include information about RRSO-related sexual problems including vaginal health, relaxation training, and body awareness;

- psychosexual interventions such as sexual-health education and rehabilitation training after risk-reducing surgery; or

- all of the above.
We compared these interventions at baseline and at various time points postintervention.

\section{Types of outcome measures}

\section{Primary outcomes}

- Quality of life: improved quality of life assessed at specified time points during or postintervention, measured using a scale that has been validated through reporting of norms in a peerreviewed publication such as the 36-Item Short Form Health Survey (SF-36), Ware 1998, or the cancer generic EORTC QLQC30 questionnaire (Fayers 2002). Menopause-Specific Quality of Life Intervention (MENQOL-Intervention) and a modified version (Hilditch 1996; Lewis 2005).

- Psychological distress: such as anxiety, depression or cancer worry measured using a scale that has been validated through reporting of norms in a peer-reviewed publication, such as Impact of Event Scale (Horowitz 1979), the Beck Depression Inventory (Beck 1974), or the General Health Questionnaire (Goldberg 1979).

\section{Secondary outcomes}

- Sexual functioning measured using a scale that has been validated through reporting of norms in a peer-reviewed publication, such as the Brief Symptom Inventory (Derogatis 1983), the Female Sexual Function Index (Rosen 2000), or the Female Sexual Distress Scale (Derogatis 2002).

- Body image measured using the Body Image Scale (Hopwood 2001).

- Psychosocial issues to include cognitive, emotional, and spiritual.

We included studies with different outcomes than those mentioned above provided that they measured the same construct.

We presented a 'Summary of findings' table for each study and reported the following outcomes listed in order of priority (see Data synthesis).

- Menopause-specific quality of life

- Psychological distress

- Sexual function

- Sexual distress

- Body image

- Sexual self-efficacy

- Sexual knowledge

- Participant satisfaction

\section{Search methods for identification of studies}

There were no language restrictions for our searches. We searched for papers in all languages and translated to English as necessary.

\section{Electronic searches}

In order to identify studies for inclusion in the review, we developed detailed search strategies for each of the following electronic databases (search date 24th April 2019).

- Cochrane Central Register of Controlled Trials (CENTRAL; 2019, Issue 4) in the Cochrane Library (Appendix 1).

- MEDLINE via Ovid (1995 to April week 2 2019) (Appendix 2). 
- Embase via Ovid (1995 to 2019 week 16) (Appendix 3).

- CINAHL (Cumulative Index to Nursing and Allied Health Literature) via Ebsco (1995 to 24 April 2019) (Appendix 4)

- PsyciNFO via Ovid (1995 to 24 April 2019 ) (Appendix 5).

- Web of Science via Web of Knowledge.com (1995 to 24 April 2019) (Appendix 6).

- Scopus via SciVerse @ Elsevir (1995 to 18 January 2018) (we used the same key terms and free text as for the other strategies).

\section{Searching other resources}

\section{Unpublished and grey literature}

- National Cancer Institute (www.cancer.gov/about-cancer/treatment/clinical-trials)(searched 25 April 2019)

- US National Institutes of Health Ongoing Trials Register ClinicalTrials.gov (clinicaltrials.gov) (searched 25 April 2019).

- ISRCTN registry (www.isrctn.com/)(searched 25 April 2019).

- EThOS (ethos.bl.uk/Home.do) (searched 25 April 2019).

\section{Handsearching}

In order to identify any unpublished studies, we handsearched the reference lists of included studies and previous systematic reviews. We searched conference abstracts from the following sources from 2010 to date.

- Association of Genetic Nurse Counsellors

- Irish Society of Human Genetics

- Cancer Genetics Spring Meeting

- European Society of Human Genetics
- International Psycho Oncology Society

- American Psycho Oncology Society

- Gynecologic Oncology (Annual Meeting of the Society of Gynecologic Oncology)

- Annual Meeting of the European Society of Medical Oncology

- American Society of Clinical Oncology

\section{Data collection and analysis}

\section{Selection of studies}

We imported all study titles identified by the searches into Covidence and removed duplicates (Covidence). Two review authors ( $\mathrm{LJ}$ and JR) independently screened the keywords, titles, and abstracts of electronic citations, excluding studies that clearly did not meet the inclusion criteria. Any disagreements were resolved by discussion amongst all review authors. Following screening, we obtained the full-text copies of potentially relevant references. Two review authors (LJ and JR) independently assessed the eligibility of the retrieved citations for inclusion. In case of differences of opinion, we planned to seek out the opinions of the other review authors (DF, PM, and MD), but this was not necessary. We planned that if additional information was needed to ascertain eligibility, we would contact the study authors, but this was not necessary. We identified and excluded duplicate reports and collated multiple reports of the same study so that each study, rather than each report, was the unit of interest in the review. We documented studies excluded after full-text assessment, providing the reasons for their exclusion in the 'Characteristics of excluded studies' table. We recorded the selection process in sufficient detail to complete a PRISMA flow diagram (Figure 1). 
Figure 1. Study flow diagram.

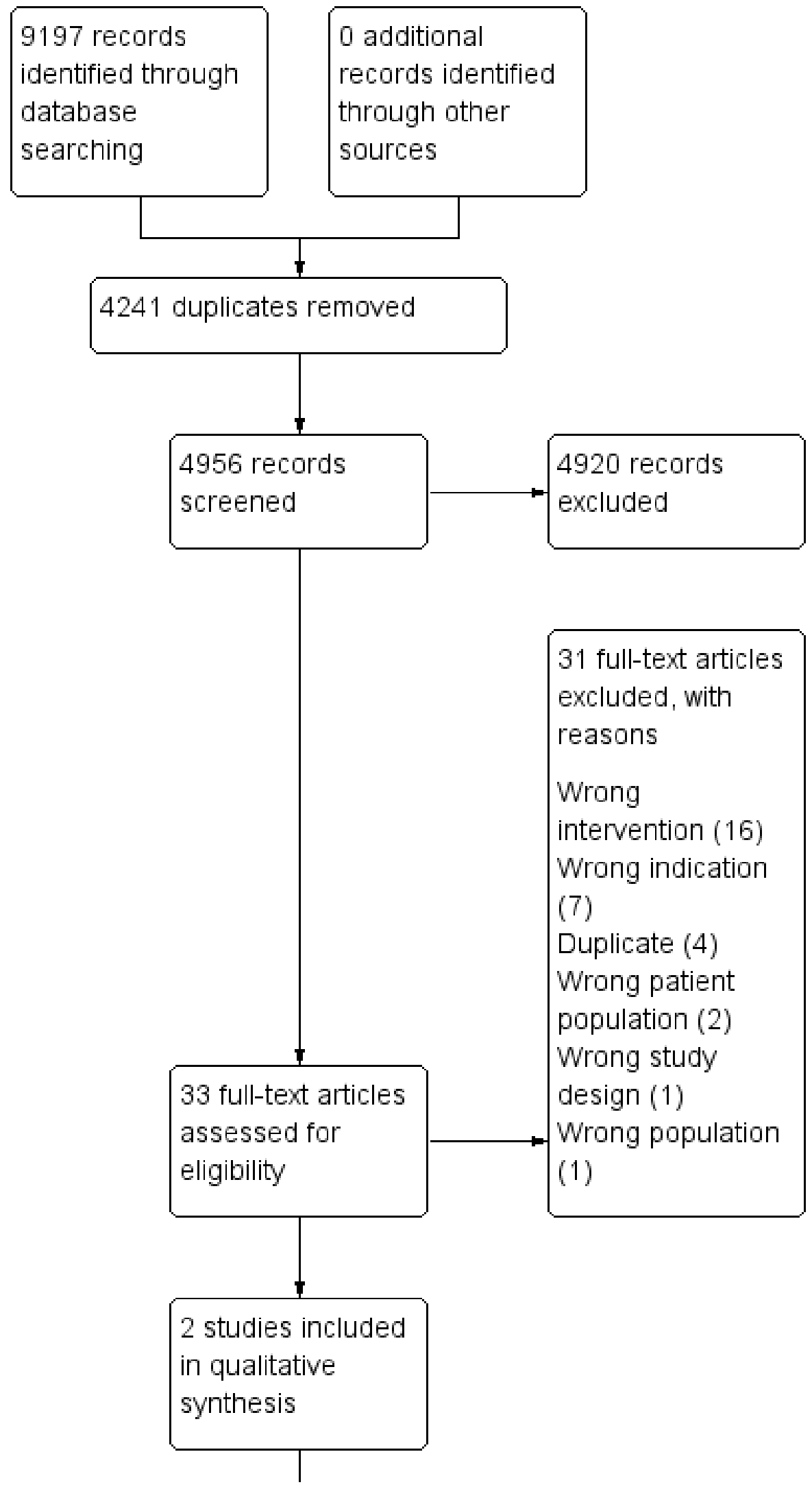


Figure 1. (Continued)

synthesis
0 studies included
in quantitative
synthesis
(meta-analysis)




\section{Data extraction and management}

Two review authors (LJ and JR) independently extracted data from the original report using a data extraction template developed in Covidence and taking guidance from the Cochrane Effective Practice and Care Group (Cochrane EPOC 2013) (Appendix 7). The template was then developed by the main review author (LJ) for the included studies. Any disagreements would have been resolved by consensus between the two review authors or amongst all review authors (LJ, JR, DF, PM, and MD), but this was not necessary.

We used the adapted data extraction template for this review and, where possible, extracted the following information from the included studies.

- Author, year of publication, and journal citation (including language).

- Country of origin.

- Aim and inclusion criteria.

- Study design, methodology.

- Study population:

* the number of participants eligible;

* participant characteristics;

* age;

* affected or healthy at risk;

* type of cancer;

* type of risk-reducing surgery;

* BRCA1 or BRCA2 mutation.

- Intervention details:

* who delivered it;

* duration and number of sessions;

* mode of delivery;

* content of intervention;

* name of validated instruments.

- Outcomes:

* definition of outcome;

* time when outcome measured, e.g. one month, six months postsurgery;

* unit of measurement.

- Results:

* the number of participants evaluated at follow-up;

* reasons for loss to follow-up;

* how study handled missing responses if stated and the actual results;

* quality of life and secondary outcome measures final values and standard deviation (SD) of outcome;

* recorded number of participants assessed at each endpoint in the treatment arm and at follow-up to estimate the mean difference (MD) between treatment arm and its standard error.

We planned that had we found more than one publication of the same study, we would use the most recent publication for data extraction and collate multiple reports of the same study as the unit of interest in the review. This was not applicable for this version of the review but may be relevant in a future update.

\section{Assessment of risk of bias in included studies}

Two review authors (LJ and JR) independently assessed the risk of bias for each included study and reported this information in the 'Risk of bias' table as described in the Cochrane Handbook for Systematic Reviews of Interventions (Higgins 2011a), and for nonrandomised studies using the ROBINS-I (Risk Of Bias In Non-randomised Studies of Interventions) tool (Sterne 2016), as shown in Table 1 and Table 2 (see Risk of bias in included studies).

\section{Measures of treatment effect}

We presented mean differences (MDs) for outcome measures on the studies included in the review. We calculated effect sizes on the basis of means, SDs to indicate the size of the change over time in the intervention group for each outcome measure in the study reviewed. In each case a 95\% confidence interval $(\mathrm{Cl})$ was generated around the MD score for each outcome measure. This was based on the standard error (SE) calculated using the number of women in the treatment arm for each outcome at the endpoints (Table 3; and Table 4).

It is unlikely that most psychosocial studies will use the same measurement scale to assess quality of life and emotional well-being and related constructs, and in such case in any future update of this review where additional studies are included, we will use the standardised mean difference (SMD). We will calculate effect sizes on the basis of means, SDs, and sample sizes for each study condition. We will also analyse the SE by number of women in the treatment arm and number of women at endpoints.

\section{Unit of analysis issues}

Had there been more than one study with a longitudinal design with repeated observations on participants, we would have defined several outcomes based on different periods of follow-up and conducted separate analyses, as recommended in the Cochrane Handbook for Systematic Reviews of Interventions (Higgins 2011a). This was unnecessary as there was only one study with repeated observations, and the mean score for all of these observations is presented in $\mathrm{Ta}$ ble 3 .

\section{Dealing with missing data}

We did not impute missing data for any of the outcomes.

\section{Assessment of heterogeneity}

As there was insufficient high-quality data in only two included studies, we did not perform a meta-analysis or any assessment of heterogeneity.

\section{Assessment of reporting biases}

We did not assess for potential reporting bias as only two studies were included in the review.

\section{Data synthesis}

As only one RCT and one NRS were included in the review, there were no appropriate data to pool.

\section{'Summary of findings' and GRADE assessment}

Where possible, we have presented the overall certainty of the evidence for each outcome (see Types of outcome measures) according to the GRADE approach, which takes into account issues not 
only related to internal validity (risk of bias, inconsistency, imprecision, publication bias) but also to external validity such as directness of results (Langendam 2013). We created a 'Summary of findings' table (Summary of findings 2) based on the methods described in the Cochrane Handbook for Systematic Reviews of Interventions (Higgins 2011a), employing GRADEpro GDT (GRADEpro GDT 2015). We used the GRADE checklist and GRADE Working Group definitions for certainty of evidence (Meader 2014).

- High-certainty: we are very confident that the true effect lies close to that of the estimate of the effect.

- Moderate-certainty: we are moderately confident in the effect estimate: the true effect is likely to be close to the estimate of the effect, but there is a possibility that it is substantially different.

- Low-certainty: our confidence in the effect estimate is limited: the true effect may be substantially different from the estimate of the effect.

- Very low-certainty: we have very little confidence in the effect estimate: the true effect is likely to be substantially different from the estimate of effect.

\section{Subgroup analysis and investigation of heterogeneity}

As only two studies were included in the review, subgroup analysis was not possible. If appropriate we will carry out subgroup analysis in future updates of the review.

\section{Sensitivity analysis}

As only two studies were included in the review, there was no need to conduct sensitivity analysis. If appropriate we will carry out sensitivity analysis in future updates of the review.

\section{RESULTS}

\section{Description of studies}

\section{Results of the search}

The search identified 9197 references, of which 4241 were duplicate references and were excluded. We screened 4956 references and excluded 4920 as irrelevant; these included editorials, commentaries, letters, and meetings abstracts. We retrieved the full-text articles for 36 references (two of which related to the same studies, leaving a total of 34 unique studies). Two review authors (LJ, JR) independently assessed these articles and excluded 34 references as they did not meet the inclusion criteria. We included two studies in the review (Bober 2015; van Driel 2019a).

\section{Included studies}

\section{Setting}

van Driel 2019a was an RCT that recruited participants from a highly specialised family cancer clinic of the university medical centre Groningen in the Netherlands.

In Bober 2015, a prospective cohort study, participants were selected from three Boston-area hospitals through clinics for women at high risk for tubo-ovarian and breast cancer, from gynaecological surgeons and patient databases at these institutions. Women were also recruited via community newsletters from Facing Our Risk of Cancer Empowered (FORCE), a national advocacy group for BRCA1 and BRCA2 women.

\section{Inclusion criteria}

van Driel 2019a included women who had undergone RRSO before the age of 52 years and reported at least two moderate-to-severe menopausal symptoms in the preceding two weeks.

Bober 2015 included English-speaking women under the age of 50 years who had undergone RRSO for tubo-ovarian cancer risk reduction one year prior to enrolment; endorsed at least one distressing symptom of sexual dysfunction on the Sexual Problem Subscale of the Sexual Function Questionnaire; and who was a BRCA1 or BRCA2 carrier.

\section{Exclusion criteria}

van Driel 2019a excluded women undergoing cancer treatment at the time of inclusion, women receiving psychiatric care, and women who had insufficient understanding of the Dutch language to allow them to complete the questionnaires.

Bober 2015 excluded women with a history of tubo-ovarian cancer, pelvic radiation, or chemotherapy within the previous year. Women with other cancers were not excluded unless active treatment had ended less than a year prior to enrolment.

\section{Study design and methodology}

van Driel 2019a was an RCT where women were randomised to an eight-week mindfulness-based stress reduction (MBSR) training programme or usual care.

Bober 2015 was a single-arm trial design without a control group. Assessments were completed at baseline and two months postintervention. This was a feasibility study so, by definition, the authors did not set out to assess effectiveness of the intervention in a rigorous manner.

\section{Study population}

van Driel 2019a included 66 participants: MBSR $(n=34)$ and usual care $(n=32)$. Women were BRCA carriers with a mean age of 47.7 years (MBSR 47.0 years, usual care 48.5 years). Of the total cohort, 17 women had a history of breast cancer, 9 in the intervention group and 8 in the control group; 31 had undergone risk-reducing mastectomy, 19 in the intervention group and 12 in the control group; and 19 were using hormone replacement therapy, 11 in the intervention group and 8 in the control group.

Bober 2015 included an evaluable sample of 37 women. Participants were all BRCA carriers with a mean age of 44.42 years $(n=$ 35). Mean years since RRSO was $3.84(n=36)$. Of the total cohort, 14 women had a history of breast cancer, and 15 were on medication for depression, anxiety, pain, or hot flashes.

\section{Intervention details}

\section{Mindfulness-based stress reduction}

In van Driel 2019a the intervention consisted of an eight-week MBSR training programme. This comprised weekly sessions of 2.5 hours each, a silent retreat evening lasting 4 hours, and a commitment to performing mindfulness-based exercises at home for 30 to $45 \mathrm{~min}$ utes 6 days a week using instructions provided on an MP3 player.

The usual care group consisted of information provided by a specialist nurse during the intake visit. This covered lifestyle advice for 
hot flashes, night sweats, vaginal dryness, sexual functioning, cardiovascular health, and bone health.

An information booklet summarising the usual care information was given to both groups, and approximately 12 weeks postrandomisation all participants were offered a repeat appointment with the nurse to address any issues.

All participants completed questionnaires at baseline and 3, 6, and 12 months postrandomisation.

\section{Validated instruments}

Menopause-specific Quality of Life questionnaire (MENQOL) (Hilditch 1996), Female Sexual Function Index (FSFI) (Rosen 2000), Female Sexual Distress Scale (FSDS) (Derogatis 2002), Generalised Anxiety Disorder 7 (GAD-7) (Spitzer 2006), Patient Health Questionnaire 2 (PHQ-2) (Kroenke 2003).

\section{Outcome}

Mindfulness-based stress reduction improved menopause-specific quality of life over both the short and long term in women with at least two moderate-to-severe menopausal symptoms after RRSO. Mindfulness-based stress reduction did not improve sexual functioning or sexual distress.

\section{Psychoeducational session}

In Bober 2015 the intervention comprised a single, half-day psychoeducational group session, take-home educational materials, and two follow-up tailored telephone counselling calls. Patient-reported assessments of sexual health and psychological functioning were completed in-person immediately prior to the psychoeducational session (baseline) and by mail two months following the session.

The intervention was facilitated by the lead investigator, a clinical psychologist, and an expert in sexual rehabilitation after cancer treatment.

The 3.5-hour group session was structured around three modules, as follows.

- Module 1: focused on psychoeducation about RRSO-related sexual problems, including improving vaginal health.

- Module 2: focused on relaxation training and body awareness.

- Module 3: was guided by principles of mindfulness-based cognitive therapy, such as addressing negative assumptions related to sexual self-esteem.

In the final portion of the group session (Module 3), women created an individual action plan. Women completed a 'Next Steps' worksheet, which identified the problems they wanted to address and at least two actionable steps that they could take based on what they had learned. It was explained that the worksheet would be reviewed during the upcoming phone call.

\section{Take-home educational materials}

Materials included instructions for mindfulness-based body scan and muscle relaxation exercises. Information about vaginal dila- tors, personal products, and resources for sexual-health websites and books.

\section{Telephone counselling}

Tailored individual telephone counselling was provided to each woman on two occasions. The first telephone session two to four weeks post-educational session dealt with remaining questions from the psychoeducational group, and action plans were reviewed and modified if needed to help women move their personalised goals forward. The second telephone counselling session was a 'booster' to help women review and consolidate their progress and plan for maintenance moving ahead.

\section{Validated instruments}

Female Sexual Function Index (FSFI) (Rosen 2000), Brief Symptom Inventory-18 (Derogatis 1983), Sexual Self-Efficacy Scale (Desrochers 2009), Sexual Knowledge Scale (Robinson 1999), participant satisfaction (Bober 2015).

\section{Outcome}

Women showed significant improvement on both sexual function and psychological distress from baseline to postintervention measured at two months.

\section{Excluded studies}

We excluded 31 studies for the following reasons.

- Twenty studies were excluded as there was no intervention, and only patient-reported outcome measures in response to questionnaires or data from medical records were used (Alamouti 2015; Altschuler 2008; Geiger 2007; Hooker 2014; Isern 2008; Julian-Reynier 2010; Kash 2000; Kim 2013; King 2009; Koslow 2013; Kotsopoulos 2017; Laarhoven 2011; Lorenz 2014; McCarthy 2017; Mutter 2015; Shigehiro 2016; Spear 2008; Tercyak 2007; Tollin 2013; Westin 2011).

- Two studies were excluded as they were concerned with decision analysis in relation to risk management (Culver 2011; Meijers-Heijboer 2000).

- Two studies were excluded as the focus was on timing of riskreducing surgery (Harmsen 2015b; Landsbergen 2010).

- Four studies were excluded as participants were not BRCA carriers or had not had risk-reducing surgery (Ackermann 2006; Fang 2006; Fang 2009; Lodder 2002).

- Two studies used an intervention of supportive expressive group therapy or enhanced counselling, but not all women had risk-reducing surgery or were BRCA carriers (Esplen 2004; Miller 2005).

- One study was a duplicate of an included study (van Driel 2019a).

\section{Risk of bias in included studies}

We evaluated risk of bias using the Cochrane 'Risk of bias' tool (Table 1) (Higgins 2011a). Results of the individual studies (one RCT and one NRS) are presented in Characteristics of included studies and Figure 2. We applied the ROBINS-1 tool to evaluate risk of bias of the NRS (Table 2). 
Figure 2. Risk of bias graph: review authors' judgements about each risk of bias item presented as percentages across all included studies.

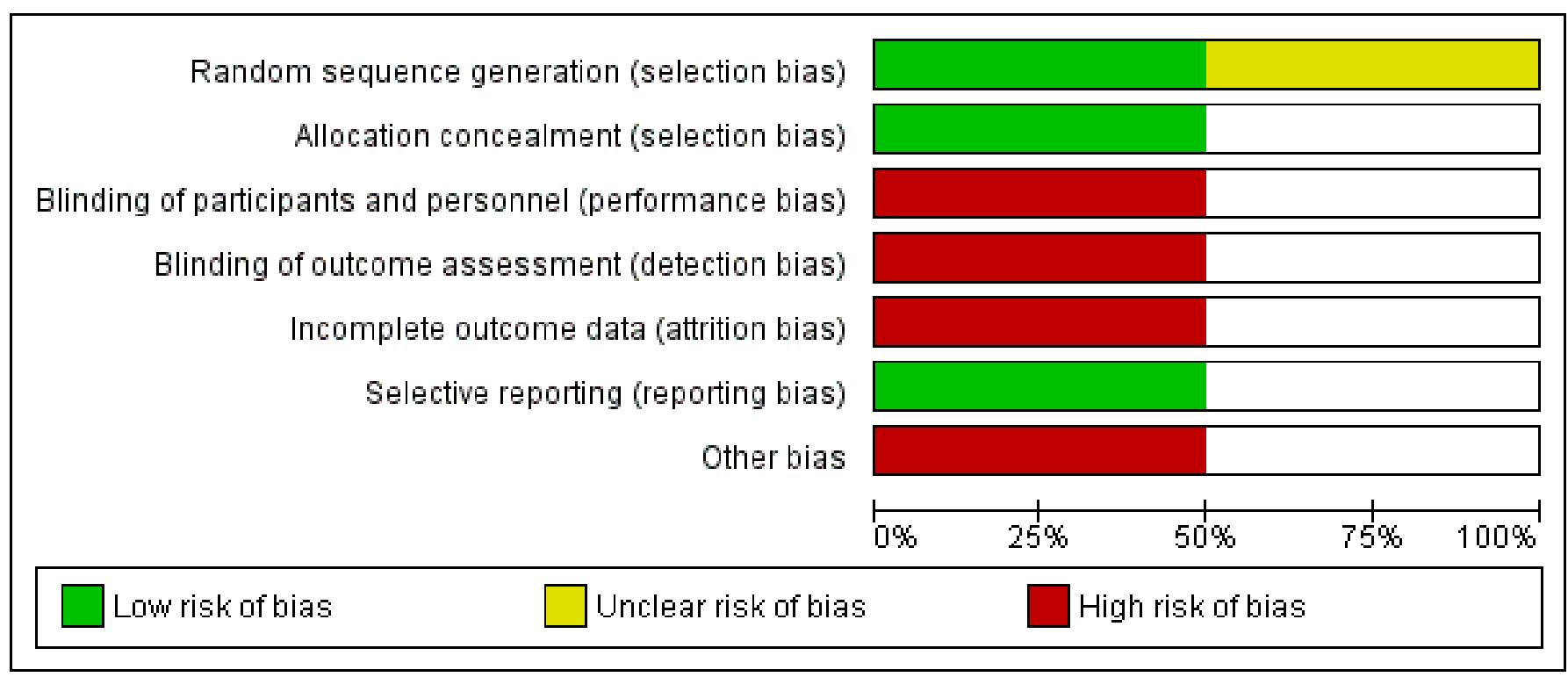

\section{Effects of interventions}

See: Summary of findings for the main comparison Mindfulness-based stress reduction training versus usual care for female BRCA carriers post-risk-reducing surgery; Summary of findings 2 Psychosocial intervention to improve sexual health versus no intervention for adult women, 18 years of age or older, who tested positive for a pathogenic mutation in BRCA1 or BRCA2 and who had had risk-reducing surgery

As two heterogenous studies were included no meta-analysis was possible. The RCT reporting MBSR was effective at improving quality of life in the short and long term for women with menopausal symptoms after RRSO as compared to usual care (van Driel 2019a); however, it was not associated with an improvement in sexual functioning or distress. The data in the Summary of findings for the main comparison reports the difference between groups at the 12 month point. At 3 (T1) and 12 (T3) months, there were improvements in the MENQOL for the MBSR group compared with the usual care group (both $\mathrm{P}=0.04)$. At 3 months, mean MENQOL scores were $3.5(95 \%$ confidence interval $(\mathrm{Cl}) 3.0$ to 3.9$)$ and $3.8(95 \% \mathrm{Cl} 3.3$ to 4.2$)$ for the MBSR and usual care groups, respectively; at 12 months, the corresponding values were $3.6(95 \% \mathrm{Cl} 3.1$ to 4.0$)$ and $3.9(95 \% \mathrm{Cl} 3.5$ to 4.4). No significant differences were found between the MBSR and usual care groups for the other scores. At randomisation (T0), $63 \%(41 / 65)$ of women reported 5 or more complaints with a bothersome score of 6 or higher (scale ranged from 1 to 8 ). Differences in improvements were found for the MENQOL total score (T1: 0.56, $\mathrm{P}=0.04$; T3: $0.56, \mathrm{P}=0.04)$ and for the vasomotor $(\mathrm{T} 1: 0.93, \mathrm{P}=$ 0.04 ; T3: $0.98, P=0.02$ ) and physical (T1: 0.65, $\mathrm{P}=0.01$; T3: $0.69, \mathrm{P}$ $=0.03$ ) subscales in the MBSR group compared with the usual care group at 3 and 12 months after the start of the intervention. At six months, there was an improvement in the MBSR group compared with the usual care group $(P=0.31)$, but there was little difference in the psychosocial and sexual subscales of the MENQOL between the MBSR and usual care group at any assessment point. A clinically relevant improvement ( $\geq 1$ improvement in MENQOL total score) was also seen in $28.6 \%$ of the MBSR group compared with $16.7 \%$ of the usual care group at T1. Regarding the secondary outcomes, $94 \%(61 / 65)$ of women reported clinically relevant sexual dysfunction, and $65 \%(42 / 65)$ reported clinically relevant sexual distress at randomisation (T0); however, there was little difference observed between the MBSR and usual care group for the FSDS and FSFI total scores or subscales at any assessment points (Summary of findings for the main comparison).

The NRS reported change in psychosexual adjustment from baseline to postintervention (median 2.3 months) using measures of FSFI $(n=34)$, which yielded change with a mean of 3.91, SD 9.12, $\mathrm{t}=2.50, \mathrm{P}=0.018$, and Cohen's $d=0.43$ (Bober 2015). The Brief Symptom Inventory, Global Severity Index yielded a mean change of 3.92, SD 5.94, $t=4.01, P<0.001$, and Cohen's $d=0.66$. The Sexual Self-Efficacy Scale yielded change with a mean of 12.14, SD 20.56, $\mathrm{t}=3.59, \mathrm{P}<0.001$, and Cohen's $d=0.59$. The Sexual Knowledge Scale $(n=36)$ reported mean change of $1.08, S D 1.50, t=4.33, P<$ 0.001 , Cohen's $d=0.72$. There was no comparison group. Women in the study showed significant improvement in overall sexual function, reduced psychological distress, and perceived sexual self-efficacy and increased knowledge about sexual side effects. Moderate-to-moderately-large change effects were reported on some of the subscales such as desire, arousal, and anxiety. There were small to moderate change effect sizes for the FSFI total score and on the subscales of satisfaction and pain as well as on the somatisation subscale. The subscales for lubrication and orgasm showed small improvement effects. We assessed the overall certainty of the evidence as very low for all outcomes (Summary of findings 2).

The participant satisfaction questionnaire showed that all 37 participants reported having enjoyed participating in the psychoeducation group, and $100 \%$ reported that they were "certain" or "very certain" that they had learned new skills to help them cope with the side effects of having their ovaries removed, whilst $98 \%$ felt more empowered to address sexual problems and 95\% reported that they were satisfied with the content of the group session. 
Body image and spiritual outcomes were not addressed by either of the studies.

The authors of this study draw attention to the essence of mindfulness-based cognitive therapy theory to help explain the differences in the size effects of the subscales for the FSFI. This therapy is focused on changing the function of the psychological event rather than changing the event itself, so for this cohort of women who had undergone RRSO, although they would be unable to change the physical impact of surgically induced menopause such as diminished intensity of orgasm and loss of lubrication resulting in discomfort, they were given the skills to learn to adapt to and positively cope with other aspects of their sexual experience. See Table 4 for the change from baseline to postintervention.

\section{DISCUSSION}

\section{Summary of main results}

We found limited evidence from two included studies reporting on different outcomes (Bober 2015; van Driel 2019a). The RCT showed that MBSR improved menopause-specific quality of life over both the short and long term in women with at least two moderate-tosevere menopausal symptoms after RRSO, but the intervention did not improve sexual functioning (van Driel 2019a). The improvement in the total MENQOL score was mainly the result of improvements in the subscales of vasomotor (i.e. burden caused by hot flushes, night sweats, and sweating in general) and physical symptoms (i.e. burden caused by stamina reduction, aches, and urination frequency). The average difference on a seven-point scale in the vasomotor subscale and the physical subscale was 0.93 and 0.65 points, respectively. Clinicians and patients could therefore expect a modest-to-moderate reduction of perceived burden (i.e. bother) by vasomotor and physical symptoms of approximately $13 \%$ and $9 \%$, respectively.

The NRS showed improvement in sexual adjustment from baseline to postintervention in women with a deleterious BRCA mutation who had RRSO but no history of ovarian cancer (Bober 2015). Almost $38 \%$ of the cohort had a history of breast cancer, but the focus of the study was psychosexual adjustment following RRSO. The limited evidence from this study also suggests that a psychosexual intervention following RRSO can improve psychological distress. The results must be interpreted with caution as they come from one small feasibility study with a very small number of participants ( $=37$ ).

Differences in study populations may explain some of the variations. Another difference was that the MBSR protocol used in the RCT was a general protocol, whereas the intervention in the NRS specifically targeted sexual difficulties. The two studies had heterogeneous populations, with some women having a diagnosis of breast cancer and some not, but the diagnosis of genetic predisposition to cancer entails psychological and physical sequelae that persist lifelong (Modaffari 2019), and this review focused on interventions for BRCA carriers with or without a cancer diagnosis.

\section{Overall completeness and applicability of evidence}

We found no studies of psychosocial interventions in female BRCA mutation carriers who had risk-reducing mastectomy. We found only one study that measured menopause-specific quality of life after RRSO.

\section{Quality of the evidence}

We assessed the certainty (quality) of the evidence as very low across studies. The decrease in certainty was the difference between an RCT and the NRS both starting at opposite ends of the GRADE ranking spectrum. Given that there were only two included studies, each with different methods, the potentially large impact if the average effect of one study differs in direction from the other, as was the case in this review, must be acknowledged. See Summary of findings 2 .

\section{Potential biases in the review process}

The search for this review was extensive and generated a number of studies, of which most were irrelevant. Searching for BRCA genes encompasses science, surgery, and cancer, and it is possible that the search was more weighted to particular outcomes. Our review was focused on a very specific group of women on which studies can be difficult to carry out as numbers are relatively small.

\section{Agreements and disagreements with other studies or reviews}

Previous studies and reviews are divided on the benefit that psychosocial interventions can offer to women with breast or gynaecological cancer, or both. These previous studies and reviews were not included in our review, as they did not meet our review criteria. Most were not specific to women with a deleterious BRCA mutation but more generally to sporadic breast cancer or gynaecological cancers.

A Cochrane Review reported on interventions for psychosexual dysfunction in women treated for gynaecological malignancy and found five RCTs of a medical or psychological intervention (Flynn 2009). The psychological interventions included access to a clinical nurse specialist, psychoeducational group therapy, and couple-coping intervention. The authors concluded that all three of these studies were of poor methodological quality.

The authors of Brotto 2012 evaluated a mindfulness-based cognitive behavioural intervention for sexual dysfunction in women who had a diagnosis of endometrial or cervical cancer. The study had a wait-list control, and results showed that the treatment led to significant improvements in all of their validated measures.

A systematic review and meta-analysis by van Driel 2019b reviewed the evidence on the effectiveness of psychological interventions in reducing symptoms associated with menopause in women who had either a natural or treatment-induced menopause. They identified 12 RCTs, and found that psychological interventions reduced hot flush bother in the short and medium term and menopausal symptoms in the short term. They also found a lack of studies reporting on the influence of psychological interventions on sexual functioning.

Significantly, Bober 2018 extended the previous work included in this review and carried out a similar psychosexual intervention on women who had received treatment for tubo-ovarian cancer. Results showed significant improvements in overall sexual functioning and psychological distress that were maintained at six months follow-up.

Applying group-based cognitive-behavioural stress management, Stagl 2015 reported on an 11-year follow-up of an RCT for women 
with breast cancer. Their results showed that women who had received cognitive-behavioural stress management in the few weeks following their surgery reported better quality of life and depressive symptoms as well as better physical and emotional well-being than those women in the control group.

Many studies have reported on quality of life in breast and tuboovarian cancer and BRCA carriers, but none following a psychosocial intervention. A systematic review by Razdan 2016 reported on quality of life among patients after bilateral prophylactic mastectomy and included 22 studies, but all used patient-reported outcomes which showed that following bilateral prophylactic mastectomy, women reported high psychosocial well-being and positive body image. The authors concluded that the methodological quality of the studies evaluated was less than ideal.

An integrative review of the literature on body image after bilateral prophylactic mastectomy in BRCA carriers highlighted the retrospective design of most of the 13 included studies (McGaughey 2006). Only two studies evaluated body image before and after bilateral prophylactic mastectomy using questionnaires or qualitative interviews, but none offered an intervention. A bibliographic review of the literature from 1974 to 2007 provided an informative and historical review of health-related quality of life in breast cancer patients (Montazeri 2008). There were no specific references to BRCA patients, as much of the data were pre-BRCA testing, but the author notes that the research in this area has made a considerable contribution to improving breast cancer care, with the caveat that the exact benefit of the studies was hard to define.

\section{AUTHORS' CONCLUSIONS}

\section{Implications for practice}

The purpose of this review was to identify psychosocial interventions available to women with a deleterious BRCA mutation who had undergone risk-reducing surgery, given that a clear need for such interventions has been identified in the literature. The lack of evidence for psychosocial interventions identified by this review raises the question of why research findings are not being translated into or further developed for use in clinical practice in the form of interventions for this group of women. The absence of such interventions highlights the need for partnership working between researchers and clinicians in this specific area. Next-generation sequencing, along with targeted cancer treatments, increasing knowledge around the biology of cancers, and the results of the $100 \mathrm{~K}$ Genome Project, will open up genetic testing to many more women. As long as surgical interventions remain the dominant riskreducing option and management of women with a deleterious BRCA gene, health professionals will have a responsibility to ensure there is provision to holistically manage the outcomes of such surgery. The authors of one study included in this review argue that if healthcare providers felt that they had resources to offer patients for treatment-related sexual dysfunction, they would be more encouraged to address these issues with them prior to surgery, which could also encourage high-risk women to choose to undergo riskreducing surgery.

Best practice is that women receive pre-test counselling prior to genetic testing. Whilst this is generally the case, and genetic counselling is offered by trained and registered genetic counsellors or geneticists, the shift to mainstreaming of genetics will see counselling being provided by surgeons and oncologists who will have had some basic level of online training in providing genetic counselling. It remains to be seen how this variance in skill level of counselling will impact patients who are making life-changing decisions based on their genetic status.

\section{Implications for research}

Whilst there are numerous studies measuring self-report psychological and quality of life outcomes following risk-reducing surgery, the next step is to take these findings forward and develop interventions to improve the psychosocial well-being of this population. As our knowledge of cancer genomics and targeted treatments develop, it is imperative that psychosocial issues are managed alongside the scientific and molecular outcomes for patients undergoing genetic testing and making life-changing decisions.

\section{ACKNOWLEDGEMENTS}

We thank Jo Morrison for clinical and editorial advice; Jo Platt for designing the search strategy; and Gail Quinn, Clare Jess, and Tracey Harrison for their contribution to the editorial process.

Mary Maguire, HSC Librarian/Subject Librarian for Allied Health, Clinical Psychology \& Health Management, HSC Library, Fern House Antrim Hospital, Antrim BT41 2RL for adapting the search strategy for other databases.

The authors and Cochrane Gynaecological, Neuro-oncology and Orphan Cancers Team are grateful to the following peer reviewers for their time and comments: Andrew Bryant, Karen Galway, Tracie Miles, Ruth Payne, and Lynn Buckley.

This project was supported by the National Institute for Health Research (NIHR), via Cochrane Infrastructure funding to the Cochrane Gynaecological, Neuro-oncology and Orphan Cancers Group. The views and opinions expressed therein are those of the review authors and do not necessarily reflect those of the Systematic Reviews Programme, the NIHR, the NHS, or the Department of Health.

This review was supported by a Cochrane Fellowship Ireland scheme from the Health and Social Care R\&D Division of the Public Health Agency (Northern Ireland), UK. 


\section{R E F E R E N C E S}

\section{References to studies included in this review}

Bober 2015 \{published data only\}

Bober S, Recklitis C, Bakan J, Garber J, Patenaude A. Addressing sexual dysfunction after risk-reducing salpingo-oophorectomy: effects of a brief, psychosexual intervention. Journal of Sexual Medicine 2015;12(1):189-197.

\section{van Driel 2019a \{published data only\}}

van Driel CMG, de Bock GH, Schroevers MJ, Mourits MJ. Mindfulness-based stress reduction for menopausal symptoms after risk-reducing salpingo-oophorectomy (PURSUE study): a randomised controlled trial. BJOG 2019;126:402-11.

\section{References to studies excluded from this review}

Ackermann 2006 \{published data only\}

Ackermann S, Lux MP, Fasching PA, Strissl P, Renner SP, Poehls U, et al. Acceptance for preventive genetic testing and prophylactic surgery in women with a family history of breast and gynaecological cancers. European Journal of Cancer Prevention 2006;15(6):474-9.

\section{Alamouti 2015 \{published data only\}}

Alamouti R, Hachach-Haram N, Farhadi J. Multidisciplinary management of risk-reducing mastectomy and immediate reconstruction: treatment algorithm and patient satisfaction. European Journal of Plastic Surgery 2015;38(5):385-90.

\section{Altschuler 2008 \{published data only\}}

Altschuler A, Nekhlyudov L, Rolnick SJ, Greene SM, Elmore JG, West CN, et al. Positive, negative, and disparate - women's differing long-term psychosocial experiences of bilateral or contralateral prophylactic mastectomy. Breast Journal 2008;14(1):25-32.

\section{Culver 2011 \{published data only\}}

Culver JO, MacDonald DJ, Thornton AA, Sand SR, Grant M, Bowen DJ, et al. Development and evaluation of a decision aid for BRCA carriers with breast cancer. Journal of Genetic Counseling 2011;20(3):294-307.

\section{Esplen 2004 \{published data only\}}

Esplen MJ, Hunter J, Leszcz M, Warner E, Narod S, Metcalfe K, et al. A multicenter study of supportive-expressive group therapy for women with BRCA1/BRCA2 mutations. Cancer 2004;101(10):2327-40.

\section{Fang 2006 \{published data only\}}

Fang CY, Daly MB, Miller SM, Zerr T, Malick J, Engstrom P. Coping with ovarian cancer risk: the moderating effects of perceived control on coping and adjustment. British Journal of Health Psychology 2006;11(4):561-80.

\section{Fang 2009 \{published data only\}}

Fang CY, Cherry C, Devarajan K, Li T, Malick J, Daly MB. A prospective study of quality of life among women undergoing risk-reducing salpingo-oophorectomy versus gynecologic screening for ovarian cancer. Gynecological Oncology 2009;112(3):594-600.

\section{Geiger 2007 \{published data only\}}

Geiger AM, Nekhlyudov L, Herrinton LJ, Rolnick SJ, Greene SM, West CN, et al. Quality of life after bilateral prophylactic mastectomy. Annals of Surgical Oncology 2007;14(2):686-94.

\section{Harmsen 2015a \{published data only\}}

Harmsen MG, Arts-de Jong M, Hoogerbrugge N, Maas AH, Prins JB, Bulten J, et al. Early salpingectomy (TUbectomy) with delayed oophorectomy to improve quality of life as alternative for risk-reducing salpingo-oophorectomy in BRCA1/2 mutation carriers (TUBA study): a prospective non-randomised multicentre study. BMC Cancer 2015;19(15):593.

\section{Hooker 2014 \{published data only\}}

Hooker GW, King L, VanHusen L, Graves K, Peshkin BN, Isaacs $C$, et al. Long-term satisfaction and quality of life following risk reducing surgery in BRCA1/2 mutation carriers. Hereditary Cancer Clinical Practice 2014;12(1):1186-97. [DOI: 10.1186/1897-4287-12-9]

\section{Isern 2008 \{published data only\}}

Isern AE, Tengrup I, Loman N, Olsson H, Ringberg A. Aesthetic outcome, patient satisfaction, and health-related quality of life in women at high risk undergoing prophylactic mastectomy and immediate breast reconstruction. Journal of Plastic, Reconstructive \& Aesthetic Surgery 2008;61(10):1177-87.

\section{Julian-Reynier 2010 \{published data only\}}

Julian-Reynier C, Bouhnik AD, Mouret-Fourme E, GauthierVillars M, Berthet $P$, Lasset $C$, et al. Time to prophylactic surgery in BRCA1/2 carriers depends on psychological and other characteristics. Genetics in Medicine 2010;12(12):801-7.

\section{Kash 2000 \{published data only\}}

Kash KM, Ortega-Verdejo K, Dabney MK, Holland JC, Miller DG, Osborne MP. Psychosocial aspects of cancer genetics: women at high risk for breast and ovarian cancer. Seminars in Surgical Oncology 2000;18(4):333-8.

Kim 2013 \{published data only\}

Kim D, Kang E, Hwang E, Sun Y, Hwang Y, Yom CK, et al. Factors affecting the decision to undergo risk-reducing salpingooophorectomy among women with BRCA gene mutation. Familial Cancer 2013;12(4):621-8.

\section{King 2009 \{published data only\}}

King HM. Risk reduction decision making in women with BRCA1/2 gene mutations. Dissertation Abstracts International: Section B: The Sciences and Engineering 2009;70(2B):1347.

\section{Koslow 2013 \{published data only\}}

Koslow S, Pharmer LA, Scott AM, Stempel M, Morrow M, Pusic AL, et al. Long-term patient-reported satisfaction after contralateral prophylactic mastectomy and implant reconstruction. Annals of Surgical Oncology 2013;20(11):3422-9. 
Kotsopoulos 2017 \{published data only\}

Kotsopoulos J, Sun P, Narod S. Bilateral oophorectomy and breast cancer risk in BRCA1 and BRCA2 mutation carriers response. Journal of the National Cancer Institute 2017;109(1):177. [DOI: 10.1093/jnci/djw177]

\section{Laarhoven 2011 \{published data only\}}

Laarhoven HWM, Prins JB, Schlooz MS, Besselink RM, Bogemann L, Koolwijk MPA, et al. Patient empowerment by group medical consultations in the follow-up of breast cancer survivors and surveillance of women with a BRCA mutation. Cancer Research 2011;71:24 Suppl 3. [DOI: 10.1158/0008-5472.SABCS11-0T3-02-03]

\section{Landsbergen 2010 \{published data only\}}

Landsbergen KM, Brunner HG, Manders P, Hoogerbrugge N, Prins JB. Educational-support groups for BRCA mutation carriers satisfy need for information but do not affect emotional distress. Genetic Counseling: Medical, Psychological, and Ethical Aspects 2010;21(4):423-37.

\section{Lodder 2002 \{published data only\}}

Lodder LN, Frets PG, Trijsburg RW, Meijers-Heijboer EJ, Klijn JG, Seynaeve C, et al. One year follow-up of women opting for presymptomatic testing for BRCA1 and BRCA2: emotional impact of the test outcome and decisions on risk management (surveillance or prophylactic surgery). Breast Cancer Research and Treatment 2002;73(2):97-112.

\section{Lorenz 2014 \{published data only\}}

Lorenz T, McGregor B, Swisher E. Relationship satisfaction predicts sexual activity following risk-reducing salpingooophorectomy. Journal of Psychosometric Obstetrics \& Gynaecology 2014;35(2):62-8.

\section{McCarthy 2017 \{published data only\}}

McCarthy CM, Hamill JB, Kim HM, Qi J, Wilkins E, Pusic AL. Impact of bilateral prophylactic mastectomy and immediate reconstruction on health-related quality of life in women at high risk for breast carcinoma: results of the Mastectomy Reconstruction Outcomes Consortium Study. Annals of Surgical Oncology 2017;24(9):2502-8.

\section{Meijers-Heijboer 2000 \{published data only\}}

Meijers-Heijboer EJ, Verhoog LC, Brekelmans CTM, Seynaeve C, Tilanus-Linthorst MMA, Wagner A, et al. Genetic testing and prophylactic surgery in familial clusters of BRCA1 or BRCA2 mutation. Gynakologe 2000;33(10):768-9.

Miller 2005 \{published data only\}

Miller SM, Roussi P, Daly MB, Buzaglo JS, Sherman K, Godwin AK, et al. Enhanced counseling for women undergoing BRCA1/2 testing: impact on subsequent decision making about risk reduction behaviors. Health Education \& Behaviour 2005;32(5):654-67.

\section{Mutter 2015 \{published data only\}}

Mutter RW, Frost MH, Hoskin TL, Johnson JL, Hartmann LC, Boughey JC. Breast cancer after prophylactic mastectomy (bilateral or contralateral prophylactic mastectomy), a clinical entity: presentation, management, and outcomes. Breast Cancer Research \& Treatment 2015;153(1):183-90.

Shigehiro 2016 \{published data only\}

Shigehiro M, Kita M, Takeuchi S, Ashihara Y, Arai M, Okamura H. Study on the psychosocial aspects of risk reducing salpingooophorectomy (RRSO) in BRCA1/2 mutation carriers in Japan: a preliminary report. Japanese Journal of Clinical Oncology 2016;46(3):254-9.

Spear 2008 \{published data only\}

Spear SL, Schwarz KA, Venturi ML, Barbosa T, Al-Attar A. Prophylactic mastectomy and reconstruction: clinical outcomes and patient satisfaction. Plastic \& Reconstruction Surgery 2008;122(1):1-9.

\section{Tercyak 2007 \{published data only\}}

Tercyak KP, Peshkin BN, Brogan BM, DeMarco T, Pennanen MF, Willey SC, et al. Quality of life after contralateral prophylactic mastectomy in newly diagnosed high-risk breast cancer patients who underwent BRCA1/2 gene testing. Journal of Clinical Oncology 2007;25(3):285-91.

Tollin 2013 \{published data only\}

Tollin S. Prophylactic, risk-reducing surgery in unaffected BRCA positive women: quality of life, sexual functioning and satisfaction with decision. Oncology Nursing Forum 11 2013;40(6,S):E447.

Westin 2011 \{published data only\}

Westin SN, Sun CC, Lu KH, Schmeler KM, Soliman PT, Lacour RA, et al. Satisfaction with ovarian carcinoma risk-reduction strategies among women at high risk for breast and ovarian carcinoma. Cancer 2011;117(12):2659-67.

\section{Additional references}

\section{Aaronson 1998}

Aaronson NK. Assessing the quality of life of patients with cancer: east meets west. European Journal of Cancer 1998;34(6):767-9.

\section{ACOG 2009}

American College of Obstetricians and Gynecologists, ACOG Committee on Practice Bulletins-Gynecology, ACOG Committee on Genetics, Society of Gynecologic Oncologists. ACOG Practice Bulletin No. 103: Hereditary breast and ovarian cancer syndrome. Obstetrics and Gynecology 2009;113(4):957-66.

\section{Antoniou 2003}

Antoniou A, Pharoah PD, Narod S, Risch HA, Eyfjord JE, Hopper JL, et al. Average risks of breast and ovarian cancer associated with BRCA1 or BRCA2 mutations detected in case series unselected for family history: a combined analysis of 22 studies. American Journal of Human Genetics 2003;72(5):117-30.

\section{Ayres 2017}

Ayres C, Ratnayake G, McNally O, Quinn M. Challenging salpingectomy as a risk-reducing measure for ovarian cancer: histopathological analysis of the tubo-ovarian interface in 
women undergoing risk-reducing salpingo-oophorectomy. International Journal of Gynecological Cancer 2017;27(4):703-7.

\section{Bai 2019}

Bai L, Arver B, Johansson H, Sandelin K, Wickman M, Brandberg Y. Body image problems in women with and without breast cancer 6-20 years after bilateral risk-reducing surgery - a prospective follow-up study. Breast 2019;44:120-7.

\section{Barofsky 2012}

Barofsky I. Can quality or quality-of-life be defined?. Quality of Life Research 2012;21(4):625-31.

\section{Beck 1974}

Beck AT, Beamesderfer A. Assessment of depression: the depression inventory. Modern Problems of Pharmacopsychiatry 1974;7(0):151-69.

\section{Bober 2018}

Bober SL, Recklitis CJ, Michaud AL, Wright AA. Improvement in sexual function after ovarian cancer: effects of sexual therapy and rehabilitation after treatment for ovarian cancer. Cancer 2018;124(1):176-82.

\section{Brandberg 2008}

Brandberg Y, Sandelin K, Erikson S, Jurell G, Liljegren A, Lindblom $A$, et al. Psychological reactions, quality of life, and body image after bilateral prophylactic mastectomy in women at high risk for breast cancer: a prospective 1-year follow-up study. Journal of Clinical Oncology 2008;26(24):3943-9.

\section{Brotto 2012}

Brotto LA, Erskine Y, Carey M, Ehlen T, Finlayson S, Heywood M, et al. A brief mindfulness-based cognitive behavioral intervention improves sexual functioning versus wait-list control in women treated for gynecologic cancer. Gynecologic Oncology 2012;125(2):320-5.

\section{Campfield Bonadies 2011}

Campfield Bonadies D, Moyer A, Matloff ET. What I wish I'd known before surgery: BRCA carriers' perspectives after bilateral salpingo-oophorectomy. Familial Cancer 2011;10(1):79-85.

\section{Chay 2016}

Chay WY, McCluggage WG, Lee CH, Köbel M, Irving J, Millar J, et al. Outcomes of incidental fallopian tube high-grade serous carcinoma and serous tubal intraepithelial carcinoma in women at low risk of hereditary breast and ovarian cancer. International Journal of Gynecological Cancer 2016;26(3):431-6.

\section{Chen 2007}

Chen S, Parmigiani G. Meta-analysis of BRCA1 and BRCA2 penetrance. Journal of Clinical Oncology 2007;25(11):1329-33.

\section{Chen 2017}

Chen F, Gaitskell K, Garcia MJ, Albukhari A, Tsaltas J, Ahmed AA. Serous tubal intraepithelial carcinomas associated with highgrade serous ovarian carcinomas: a systematic review. BJOG 2017;124(6):872-8.

\section{Cochrane EPOC 2013}

Effective Practice, Organisation of Care (EPOC). Data collection form. EPOC Resources for review authors. Oslo: Norwegian Knowledge Centre for the Health Services; 2013. epoc.cochrane.org/epoc-specific-resources-review-authors (accessed 9 June 2017).

\section{Crum 2013}

Crum CP, Herfs M, Ning G, Bijron JG, Howitt BE, Jimenez CA, et al. Through the glass darkly: intraepithelial neoplasia, topdown differentiation, and the road to ovarian cancer. Journal of Pathology 2013;231(4):402-12.

\section{De Felice 2015}

De Felice F, Marchetti C, Musella A, Palaia I, Perniola G, Musio D, et al. Bilateral risk-reduction mastectomy in BRCA1 and BRCA2 mutation carriers: a meta-analysis. Annals of Surgical Oncology 2015;22(9):2876-80.

\section{Deeks 2001}

Deeks JJ. Systematic reviews in health care: systematic reviews of evaluations of diagnostic and screening tests. $B M J$ 2001;323(7305):157-62.

\section{den Heijer 2012}

den Heijer M, Seynaeve C, Timman R, Duivenvoorden HJ, Vanheusden $\mathrm{K}$, Tilanus-Linthorst $\mathrm{M}$, et al. Body image and psychological distress after prophylactic mastectomy and breast reconstruction in genetically predisposed women: a prospective long-term follow-up study. European Journal of Cancer 2012;48(9):1263-8.

\section{Derogatis 1983}

Derogatis LR, Melisaratos N. The Brief Symptom Inventory: an introductory report. Psychological Medicine 1983;13(3):595-605.

\section{Derogatis 2002}

Derogatis LR, Rosen R, Leiblum S, Burnett A, Heiman J. The Female Sexual Distress Scale (FSDS): initial validation of a standardized scale for assessment of sexually related personal distress in women. Journal of Sex and Marital Therapy 2002;28(4):317-30.

\section{Desrochers 2009}

Desrochers G, Bergeron S, Khalifé S, Dupuis MJ, Jodoin M. Fear avoidance and self-efficacy in relation to pain and sexual impairment in women with provoked vestibulodynia. Clinical Journal of Pain 2009;25(6):520-7.

\section{Egger 1997}

Egger M, Smith GD, Phillips AN. Meta-analysis: principles and procedures. BMJ 1997;315(7121):1533-7.

\section{Eleje 2016}

Eleje GU, Eke AC, Ezebialu IU, Ikechebelu JI, Ugwu EO, Okonkwo 00. Risk-reducing bilateral salpingo-oophorectomy in women with BRCA1 or BRCA2 mutations. Cochrane Database of Systematic Reviews 2016, Issue 12. [DOI: 10.1002/14651858.CD012464] 


\section{Euhus 2015}

Euhus DM. Risk-reducing mastectomy for BRCA gene mutation carriers. Annals of Surgical Oncology 2015;22(9):2807-9.

\section{Evans 2015}

Evans DG, Wisely J, Clancy T, Lalloo F, Wilson M, Johnson R, et al. Longer term effects of the Angelina Jolie effect: increased risk-reducing mastectomy rates in BRCA carriers and other highrisk women. Breast Cancer Research 2015;17:143.

\section{Fayers 2002}

Fayers P, Bottomley A, EORTC Quality of Life Group, Quality of Life Unit. Quality of life research within the EORTC - the EORTC QLQ-C30. European Journal of Cancer 2002;38(Suppl 4):S125-33.

\section{Finch 2011}

Finch A, Narod SA. Quality of life and health status after prophylactic salpingo-oophorectomy in women who carry a BRCA mutation: a review. Maturitas 2011;70(3):261-5.

\section{Finch 2013}

Finch A, Metcalfe KA, Chiang J, Elit L, McLaughlin J, Springate C, et al. The impact of prophylactic salpingo-oophorectomy on quality of life and psychological distress in women with a BRCA mutation. Psycho-Oncology 2013;22(1):212-9.

\section{Flynn 2009}

Flynn P, Kew F, Kisely SR. Interventions for psychosexual dysfunction in women treated for gynaecological malignancy. Cochrane Database of Systematic Reviews 2009, Issue 2. [DOI: 10.1002/14651858.CD004708.pub2]

\section{Ford 1998}

Ford D, Easton DF, Stratton M, Narod S, Goldgar D, Devilee P, et al. Genetic heterogeneity and penetrance analysis of the BRCA1 and BRCA2 genes in breast cancer families. The Breast Cancer Linkage Consortium. American Journal of Human Genetics 1998;62(3):676-89.

\section{Foster 2007}

Foster C, Watson M, Eeles R, Eccles D, Ashley S, Davidson R, et al. Predictive genetic testing for $B R C A 1 / 2$ in a UK clinical cohort: three-year follow-up. British Journal of Cancer 2007;96(5):718-24.

\section{Frühauf 2013}

Frühauf S, Gerger H, Schmidt HM, Munder T, Barth J. Efficacy of psychological interventions for sexual dysfunction: a systematic review and meta-analysis. Archives of Sexual Behavior 2013;42(6):915-33.

\section{Gahm 2010}

Gahm J, Wickman M, Brandberg Y. Bilateral prophylactic mastectomy in women with inherited risk of breast cancer prevalence of pain and discomfort, impact on sexuality, quality of life and feelings of regret two years after surgery. Breast 2010;19(6):462-9.

\section{Gahm 2013}

Gahm J, Hansson P, Brandberg Y, Wickman M. Breast sensibility after bilateral risk-reducing mastectomy and immediate breast reconstruction: a prospective study. Journal of Plastic, Reconstructive \& Aesthetic Surgery 2013;66(11):1521-7.

\section{Galway 2012}

Galway K, Black A, Cantwell M, Cardwell C, Mills M, Donnelly M. Psychosocial interventions to improve quality of life and emotional wellbeing for recently diagnosed cancer patients. Cochrane Database of Systematic Reviews 2012, Issue 11. [DOI: 10.1002/14651858.CD007064.pub2]

\section{Genomics England 2019}

Genomics England. www.genomicsengland.co.uk (accessed 9 May 2019).

\section{Goldberg 1979}

Goldberg DP, Hillier VF. A scaled version of the General Health Questionnaire. Psychological Medicine 1979;9(1):139-45.

\section{Gopie 2013}

Gopie JP, Mureau MA, Seynaeve C, Ter Kuile MM, MenkePluymers MB, Timman R, et al. Body image issues after bilateral prophylactic mastectomy with breast reconstruction in healthy women at risk for hereditary breast cancer. Familial Cancer 2013;12(3):479-87.

\section{GRADEpro GDT 2015 [Computer program]}

McMaster University (developed by Evidence Prime). GRADEpro GDT. Version accessed 5 June 2017. Hamilton (ON): McMaster University (developed by Evidence Prime), 2015.

\section{Hall 2019}

Hall E, Finch A, Jacobson M, Rosen B, Metcalfe K, Sun P, et al. Effects of bilateral salpingo-oophorectomy on menopausal symptoms and sexual functioning among women with a BRCA1 or BRCA2 mutation. Gynecologic Oncology 2019;152:145-50.

\section{Hallowell 2012}

Hallowell N, Baylock B, Heiniger L, Butow PN, Patel D, Meiser B, et al. Looking different, feeling different: women's reactions to risk-reducing breast and ovarian surgery. Familial Cancer 2012;11(2):215-24.

\section{Harmsen 2015b}

Harmsen MG, Hermens RP, Prins JB, Hoogerbrugge N, de Hullu JA. How medical choices influence quality of life of women carrying a BRCA mutation. Critical Reviews in Oncology/ Hematology 2015;96(3):555-68.

\section{Hartmann 2016}

Hartmann LC, Lindor NM. Risk-reducing surgery in hereditary breast and ovarian cancer. New England Journal of Medicine 2016;374(24):2404.

\section{Higgins 2003}

Higgins JPT, Thompson SG, Deeks JJ, Altman DG. Measuring inconsistency in meta-analyses. BMJ 2003;327(7414):557-60.

\section{Higgins 2011a}

Higgins JPT, Green S, editor(s). Cochrane Handbook for Systematic Reviews of Interventions Version 5.1.0 (updated 
March 2011). The Cochrane Collaboration, 2011. Available from handbook.cochrane.org.

\section{Higgins 2011b}

Higgins JPT, Altman DG, Sterne JAC, editor(s). Chapter 8: Assessing risk of bias in included studies. In: Higgins JP, Green $\mathrm{S}$, editor(s). Cochrane Handbook for Systematic Reviews of Interventions Version 5.1.0 (updated March 2011). The Cochrane Collaboration, 2011. Available from handbook.cochrane.org.

\section{Hilditch 1996}

Hilditch JR, Lewis J, Peter A, van Maris B, Ross A, Franssen E, et al. A menopause-specific quality of life questionnaire: development and psychometric properties. Maturitas 1996;24:107-21.

\section{Hopwood 2000}

Hopwood P, Lee A, Shenton A, Baildam A, Brain A, Lalloo F, et al. Clinical follow-up after bilateral risk reducing ('prophylactic') mastectomy: mental health and body image outcomes. PsychoOncology 2000;9(6):462-72.

\section{Hopwood 2001}

Hopwood P, Fletcher I, Lee A, Al Ghazal S. A body image scale for use with cancer patients. European Journal of Cancer 2001;37(2):189-97.

\section{Horowitz 1979}

Horowitz M, Wilner N, Alvarez W. Impact of Event Scale: a measure of subjective stress. Psychosomatic Medicine 1979;41(3):209-18

\section{Jeffers 2014}

Jeffers L, Morrison PJ, McCaughan E, Fitzsimons D. Maximising survival: the main concern of women with hereditary breast and ovarian cancer who undergo genetic testing for BRCA1/2. European Journal of Oncology Nursing 2014;18(4):411-8.

\section{King 2003}

King MC, Marks JH, Mandell JB, New York Breast Cancer Study Group. Breast and ovarian cancer risks due to inherited mutations in BRCA1 and BRCA2. Science 2003;302(5645):643-6.

\section{Kroenke 2003}

Kroenke K, Spitzer RL, Williams JBW. The patient health questionnaire-2. Medical Care 2003;41:1284-92.

\section{Langendam 2013}

Langendam MW, Akl EA, Dahm P, Glasziou P, Guyatt G, Schünemann HJ. Assessing and presenting summaries of evidence in Cochrane Reviews. Systematic Reviews 2013;23(2):81.

\section{Lengacher 2009}

Lengacher CA, Johnson-Mallard V, Post-White J, Moscoso MS, Jacobsen PB, Klein TW, et al. Randomized controlled trial of mindfulness-based stress reduction (MBSR) for survivors of breast cancer. Psycho-Oncology 2009;18(12):1261-72.

\section{Lewis 2005}

Lewis JE, Hilditch JR, Wong CJ. Further psychometric property development of the Menopause-Specific Quality of Life questionnaire and development of a modified version, MENQOL-Intervention questionnaire. Maturitas 2005;50(3):209-21.

\section{Matloff 2009}

Matloff ET, Barnett RE, Bober SL. Unraveling the next chapter: sexual development, body image, and sexual functioning in female BRCA carriers. Cancer Journal 2009;15(1):15-8.

\section{Mavaddat 2013}

Mavaddat N, Peock S, Frost D, Ellis S, Platte R, Fineberg E, et al. EMBRACE. Cancer risks for BRCA1 and BRCA2 mutation carriers: results from prospective analysis of EMBRACE. Journal of the National Cancer Institute 2013;105(11):812-22.

\section{McAlpine 2012}

McAlpine JN, Porter H, Köbel M, Nelson BH, Prentice LM, Kalloger SE, et al. BRCA1 and BRCA2 mutations correlate with TP53 abnormalities and presence of immune cell infiltrates in ovarian high-grade serous carcinoma. Modern Pathology 2012;25(5):740-50.

\section{McGaughey 2006}

McGaughey A. Body image after bilateral prophylactic mastectomy: an integrative literature review. Journal of Midwifery \& Women's Health 2006;51(6):e45-9. [DOI: 10.1016/ j.jmwh.2006.07.002]

\section{Meader 2014}

Meader N, King K, Llewellyn A, Norman G, Brown J, Rodgers M, et al. A checklist designed to aid consistency and reproducibility of GRADE assessments: development and pilot validation. Systematic Reviews 2014;3:82.

\section{Metcalfe 2004}

Metcalfe KA, Esplen MJ, Goel V, Narod SA. Psychosocial functioning in women who have undergone bilateral prophylactic mastectomy. Psycho-Oncology 2004;13(1):14-25.

\section{Modaffari 2019}

Modaffari P, Ponzone P, Ferrari A, Cipullo I, Liberale V, D'Alonzo $\mathrm{M}$, et al. Concerns and expectations of risk-reducing surgery in women with hereditary breast and ovarian cancer syndrome. Journal of Clinical Medicine 2019;8(3):313. [DOI: $10.3390 / j \mathrm{~cm} 8030313]$

\section{Montazeri 2008}

Montazeri A. Health-related quality of life in breast cancer patients: a bibliographic review of the literature from 1974 to 2007. Journal of Experimental \& Clinical Cancer Research 2008;27:32. [DOI: 10.1186/1756-9966-27-32]

\section{NHS England 2015}

NHS England. Clinical Commissioning Policy: Genetic testing for BRCA1 and BRCA2 mutations. www.england.nhs.uk/ commissioning?s=BRCA (accessed 16 September 2017). 


\section{NICE 2013}

National Institute for Health and Care Excellence. Familial breast cancer: classification and care of people at risk of familial breast cancer and management of breast cancer and related risks in people with a family history of breast cancer. Clinical guideline. www.nice.org.uk/guidance/cg164 (accessed prior to 18 September 2019).

\section{Razdan 2016}

Razdan SN, Patel V, Jewell S, McCarthy CM. Quality of life among patients after bilateral prophylactic mastectomy: a systematic review of patient-reported outcomes. Quality of Life Research 2016;25(6):1409-21.

\section{Resta 2006}

Resta R, Biesecker BB, Bennett RL, Blum S, Hahn SE, Strecker MN, et al. A new definition of genetic counseling: National Society of Genetic Counselor's Task Force report. Journal of Genetic Counseling 2006;15(2):77-83.

\section{RevMan 2014 [Computer program]}

Nordic Cochrane Centre, The Cochrane Collaboration. Review Manager 5 (RevMan 5). Version 5.3. Copenhagen: Nordic Cochrane Centre, The Cochrane Collaboration, 2014.

\section{Robinson 1999}

Robinson JW, Faris PD, Scott CB. Psychoeducational group increases vaginal dilation for younger women and reduces sexual fears for women of all ages with gynecological carcinoma treated with radiotherapy. International Journal of Radiation Oncology \& Biological Physics 1999;44(3):497-506.

\section{Robson 2003}

Robson M, Hensley M, Barakat R, Brown C, Chi D, Poynor E, et al. Quality of life in women at risk for ovarian cancer who have undergone risk-reducing oophorectomy. Gynecologic Oncology 2003;89(2):281-7.

\section{Rosen 2000}

Rosen R, Brown C, Heiman J, Leiblum S, Meston C, Shabsigh R, et al. The Female Sexual Function Index (FSFI): a multidimensional self-report instrument for the assessment of female sexual function. Journal of Sex \& Marital Therapy 2000;26(2):191-208.

\section{Rosenberg 2016}

Rosenberg SM, Ruddy KJ, Tamimi RM, Gelber S, Schapira L, Come $\mathrm{S}$, et al. BRCA1 and BRCA2 mutation testing in young women with breast cancer. JAMA Oncology 2016;2(6):730-6.

\section{Rosenthal 2017}

Rosenthal AN, Fraser LS, Philpott S, Manchanda R, Burnell M, Badman $\mathrm{P}$, et al. Evidence of stage shift in women diagnosed with ovarian cancer during Phase II of the United Kingdom Familial Ovarian Cancer Screening Study. Journal of Clinical Oncology 2017;35(13):1411-20.

\section{Skirton 2010}

Skirton H, Patch C, Voelckel MA. Using a community of practice to develop standards of practice and education for genetic counsellors in Europe. Journal of Community Genetics 2010;1(4):169-73.

\section{Spitzer 2006}

Spitzer RL, Kroenke K, Williams JBW, Lowe B. A brief measure for assessing generalised anxiety disorder. Archives of Internal Medicine 2006;166:1092.

\section{Stagl 2015}

Stagl JM, Lechner SC, Carver CS, Bouchard LC, Gudenkauf LM, Jutagir DR, et al. A randomized controlled trial of cognitivebehavioral stress management in breast cancer: survival and recurrence at 11-year follow-up. Breast Cancer Research \& Treatment 2015;154(2):319-28.

\section{Stan 2013}

Stan DL, Shuster LT, Wick MJ, Swanson CL, Pruthi S, BakkumGamez JN. Challenging and complex decisions in the management of the BRCA mutation carrier. Journal of Women's Health 2013;22(10):825-34.

\section{Sterne 2016}

Sterne JA, Hernán MA, Reeves BC, Savović J, Berkman ND, Viswanathan M, et al. ROBINS-I: a tool for assessing risk of bias in non-randomised studies of interventions. BMJ 2016;355:i4919.

\section{Unukovych 2012}

Unukovych D, Sandelin K, Wickman M, Arver B, Johansson H, Brandberg Y, et al. Breast reconstruction in patients with personal and family history of breast cancer undergoing contralateral prophylactic mastectomy, a 10-year experience. Acta Oncologica 2012;51(7):934-41.

\section{van Driel 2019b}

van Driel CM, Stuursma A, Schroevers MJ, Mourits MJ, de Bock GH. Mindfulness, cognitive behavioural and behaviourbased therapy for natural and treatment-induced menopausal symptoms: a systematic review and meta-analysis. BJOG 2019;126:330-9.

\section{van Oostrom 2003}

van Oostrom I, Meijers-Heijboer H, Lodder LN, Duivenvoorden HJ, van Gool AR, Seynaeve C, et al. Long-term psychological impact of carrying a BRCA1/2 mutation and prophylactic surgery: a 5-year follow-up study. Journal of Clinical Oncology 2003;21(20):3867-74.

\section{Ware 1998}

Ware JE Jr, Gandek B. Overview of the SF-36 Health Survey and the International Quality of Life Assessment (IQOLA) Project. Journal of Clinical Epidemiology 1998;51(11):903-12.

\section{Watson 2004}

Watson M, Foster C, Eeles R, Eccles D, Ashley S, Davidson R, et al. Psychosocial impact of breast/ovarian (BRCA1/2) cancerpredictive genetic testing in a UK multi-centre clinical cohort. British Journal of Cancer 2004;91(10):1787-94. 


\section{References to other published versions of this review}

\section{Jeffers 2017}

Jeffers L, Reid J, Fitzsimons D, Morrison PJ, Dempster M.

Interventions to improve psychosocial well-being in female

\section{CHARACTERISTICS OF STUDIES}

Characteristics of included studies [ordered by study ID]

\section{Bober 2015}

\begin{tabular}{ll}
\hline Methods & Prospective cohort study \\
\hline Participants & $\begin{array}{l}\text { BRCA1, BRCA2 mutation carriers. } 37 \text { participants enrolled. All had risk-reducing bilateral salpin- } \\
\text { go-oophorectomy. Have at least } 1 \text { distressing symptom of sexual dysfunction }\end{array}$ \\
\hline Interventions & $\begin{array}{l}\text { Psychosexual intervention integrating elements of cognitive behavioural therapy with sexual health } \\
\text { education }\end{array}$ \\
\hline Outcomes & Sexual function: desire, arousal, lubrication, orgasm, satisfaction, pain \\
& Psychological distress: somatisation, depression, anxiety \\
& Sexual self-efficacy \\
& Sexual knowledge
\end{tabular}

Notes

\section{Risk of bias}

\begin{tabular}{lll} 
Bias & Authors' judgement & Support for judgement \\
\hline $\begin{array}{l}\text { Random sequence genera- } \\
\text { tion (selection bias) }\end{array}$ & Unclear risk & See Table 2 \\
\hline
\end{tabular}

BRCA-mutation carriers following risk-reducing surgery. Cochrane Database of Systematic Reviews 2017, Issue 12. [DOI: 10.1002/14651858.CD012894]

van Driel 2019a

\begin{tabular}{|c|c|c|}
\hline Methods & \multicolumn{2}{|c|}{ Randomised controlled trial } \\
\hline Participants & \multicolumn{2}{|c|}{$\begin{array}{l}66 \text { female BRCA carriers who had undergone risk-reducing salpingo-oophorectomy before the age of } 52 \\
\text { years and reported at least } 2 \text { moderate-to-severe menopausal symptoms in the } 2 \text { weeks prior to enrol- } \\
\text { ment }\end{array}$} \\
\hline Interventions & \multicolumn{2}{|c|}{ Mindfulness-based stress reduction training over an 8-week period vs usual care } \\
\hline Outcomes & \multicolumn{2}{|c|}{ Menopause-specific quality of life, sexual function, and sexual distress } \\
\hline \multicolumn{3}{|l|}{ Notes } \\
\hline \multicolumn{3}{|l|}{ Risk of bias } \\
\hline Bias & Authors' judgement & Support for judgement \\
\hline $\begin{array}{l}\text { Random sequence genera- } \\
\text { tion (selection bias) }\end{array}$ & Low risk & $\begin{array}{l}\text { Block randomisation performed by independent trial co-ordination centre via } \\
\text { a web application using a computerised random number generator }\end{array}$ \\
\hline
\end{tabular}


van Driel 2019a (Continued)

Allocation concealment $\quad$ Low risk
(selection bias)

Blinding of participants

High risk

Very serious risk of bias due to lack of blinding of participants and personnel, and personnel (perforattrition bias, and self-selection bias mance bias)

All outcomes

Blinding of outcome assessment (detection bias)

All outcomes
High risk

Due to the nature of the intervention assessors would be aware of the group

\section{Incomplete outcome data High risk} (attrition bias)

High loss to follow-up (outcomes only available for 48 of 66 enrolled partici-

All outcomes

\begin{tabular}{lll}
\hline $\begin{array}{l}\text { Selective reporting (re- } \\
\text { porting bias) }\end{array}$ & Low risk & Study reported numbers of participants at each time point \\
\hline Other bias & High risk & $\begin{array}{l}\text { Self-selection bias as only one-third of eligible women chose to participate in } \\
\text { the study }\end{array}$
\end{tabular}

\section{Characteristics of excluded studies [ordered by study ID]}

\begin{tabular}{ll}
\hline Study & Reason for exclusion \\
\hline Ackermann 2006 & Wrong population, not BRCA carriers and had not undergone risk-reducing surgery. \\
& $\begin{array}{l}\text { Indication of study was the acceptance for genetic testing of untested women with a positive fami- } \\
\text { ly history and their attitude toward prophylactic surgery. }\end{array}$
\end{tabular}

Alamouti $2015 \quad \begin{aligned} & \text { Questionnaire and PROMs } \\ & \text { Women completed a validated Breast-Q questionnaire detailing their experience in a number } \\ & \text { of domains including body image and perception, sexuality, and cosmetic outcome after their } \\ & \text { surgery. They also attended an individual interview for further analysis of patient experience and } \\ & \text { expectations, but there was no psychosocial intervention. }\end{aligned}$

Altschuler $2008 \quad$ Questionnaire and PROMs

The study explored the nuances of women's satisfaction with risk-reducing mastectomy using a qualitative, open-ended format as part of a mailed survey.

Culver $2011 \quad$ Wrong intervention

The study indicator was decision-making needs and the use of a decision aid as an adjunct to genetic counselling. Phase 1 used focus group.

Esplen $2004 \quad$ Wrong indicator, and most women had not had risk-reducing surgery prior to intervention
of 12 sessions of supportive-expressive group therapy that lasted 6 months. Before and after mea-
sures of psychosocial functioning, knowledge, and surveillance/surgery activities were completed.
During the intervention and postintervention some participants underwent risk-reducing surgery.

Fang 2006 No intervention. Assessments of problem-focused coping, perceived control and distress were collected upon entry into the programme and again at 3-month follow-up. Behavioural adherence 


\begin{tabular}{ll}
\hline Study & Reason for exclusion \\
\hline & $\begin{array}{l}\text { to screening during the 12-month period following programme entry was obtained from clinic } \\
\text { records. }\end{array}$ \\
\hline
\end{tabular}

The primary objective of the study was to prospectively assess quality of life among women at increased risk for tubo-ovarian cancer who were undergoing RRSO or serial screening. Participants were considering RRSO due to: 1) a family history of tubo-ovarian cancer, 2) a family history suggestive of a hereditary breast/ovarian pattern, and/or 3) the presence of a known disease-related gene mutation in the family.

\begin{tabular}{ll}
\hline Geiger 2007 & Questionnaire and PROMs \\
& Retrospective data collected through a mailed survey
\end{tabular}

Harmsen 2015a

Wrong intervention - timing of surgical intervention. The indicator was the time participants chose to undergo standard RRSO (at age 35 to 40 (BRCA1) or 40 to 45 (BRCA2)) or an alternative strategy (risk-reducing surgery upon completion of childbearing and RRSO at age 40 to 45 (BRCA1) or 45 to 50 (BRCA2)).

\section{Hooker 2014}

Questionnaire and PROMs

Data collected through a mailed survey.

Isern $2008 \quad$ Surgical indication

Indicator was the clinical evaluation of aesthetic results and complications. Patient satisfaction and quality of life were evaluated with 1 study-specific and 2 standardised health-related questionnaires administered at time of clinical follow-up.

Wrong indication - timing to risk-reducing surgery

The aim of this prospective study was to investigate the psychosocial and medical factors that determine timing of prophylactic surgery in women carriers of a deleterious BRCA1 or BRCA2 mutation.

\section{Kash 2000}

Not all women had risk-reducing surgery. PROMs

Women completed a questionnaire about genetic testing, psychological distress, and health beliefs.

Kim $2013 \quad \begin{aligned} & \text { Wrong indication. No intervention } \\ & \text { The objective of this study was to identify factors that affect the decision to undergo RRSO in BR- } \\ & \text { CA1 or BRCA2 mutations carriers in South Korea. Medical records were reviewed to collect data. }\end{aligned}$

Wrong population, as not all had undergone risk-reducing surgery. PROMs

"137 unaffected, positive BRCA1/2 gene mutation carriers (42 who opted for prophylactic mastectomy, 95 who did not) served as participants. All women completed an on-line battery that assessed the following theory-based decision making variables: advantages and disadvantages of prophylactic mastectomy (normative decision theory), physician recommendation (shared decision making theory), cancer worry (affect theory), and information-seeking coping style."

Indicator was whether satisfaction and health-related quality of life differ between women who do and who do not undergo CPM in the setting of implant reconstruction using the BREAST-Q, a validated patient-reported outcome instrument. 


\begin{tabular}{ll}
\hline Study & Reason for exclusion \\
\hline Kotsopoulos 2017 & Wrong indication, PROMs \\
& $\begin{array}{l}\text { Whether or not bilateral oophorectomy reduces breast cancer risk among women with a BRCA1 } \\
\text { or BRCA2 mutation. Data collected from questionnaires or by phone by a genetic counsellor or re- } \\
\text { search assistant. }\end{array}$
\end{tabular}

Laarhoven 2011 Not all women had risk-reducing surgery. Design for randomised controlled trial
In order to fulfil the needs for psychosocial support and information, the study introduced group
medical consultations. Primary outcome measures were empowerment and psychological distress
(SCL 90). Secondary outcome measures were fear of cancer, information needs before the consul-
tation and the received information, self-examination of the breasts, patient satisfaction, quality of
life, and cost-effectiveness. Data were collected via self-reported questionnaires 1 week before the
visit and at 1-week and 3-month follow-up.

Landsbergen 2010

Not all women had undergone risk-reducing surgery. Wrong indication - decision making

Female BRCA mutation carriers were approached by a social worker after genetic test disclosure and offered participation in educational-support groups to meet their needs regarding BRCA-related information in order to support decision-making processes regarding cancer surveillance or prophylactic surgery.

Lodder 2002

PROMS

26 women were identified as BRCA1/BRCA2 mutation carriers and 37 as non-mutation carriers. Not all the mutation carriers had risk-reducing surgery. Study also included partners.

Lorenz $2014 \quad \begin{aligned} & \text { Wrong population - not BRCA carriers } \\ & \text { A secondary analysis of quality of life measures collected in } 85 \text { women at high risk for tubo-ovarian } \\ & \text { cancer. Participants completed validated measures of mental, physical, and relationship health. }\end{aligned}$

McCarthy $2017 \quad$ Wrong indication - timing for risk-reducing mastectomy and reconstruction and PROMs.

Patient-reported outcome data were prospectively collected as part of the Mastectomy Reconstruction Outcomes Consortium Study, and data on a subgroup of 204 high-risk women who elected to have risk-reducing mastectomy and immediate reconstruction were evaluated.

\begin{tabular}{ll}
\hline Meijers-Heijboer 2000 & Decision-making behaviour \\
\hline Miller 2005 & Wrong indication. Not all women will had risk-reducing surgery \\
& The indicator was genetic counselling or enhanced genetic counselling to help participants antici- \\
& pate their reactions to possible test outcomes and plan for postresult consequences. \\
\hline
\end{tabular}

Mutter $2015 \quad$ Wrong indication, medical outcomes. PROMs

Medical records were reviewed, and study-specific questionnaires were sent to all women.

Shigehiro $2016 \quad$ Wrong study design. Qualitative interviews and PROMs

Worry about cancer, emotional state, and cancer-specific distress level were evaluated using a 4point Likert scale, the Profile of Mood States-Short Form, and the Impact of Event Scale-Revised, respectively, before and 1 year after the surgery. In addition, participants were interviewed regarding their expectations for the risk-reducing surgery, the effects of the surgery, and recovery from surgery, before surgery and at 1,6 , and 12 months after surgery.

Spear $2008 \quad$ Wrong indication, wrong intervention




\begin{tabular}{|c|c|}
\hline Study & Reason for exclusion \\
\hline & $\begin{array}{l}\text { Timing, type of mastectomy and reconstruction, complications, and cancer occurrence/recurrence } \\
\text { were examined. Participants reported their level of satisfaction and willingness to undergo the pro- } \\
\text { cedure again. }\end{array}$ \\
\hline \multirow[t]{2}{*}{ Tercyak 2007} & Wrong indication, wrong population - only 15\% BRCA carriers \\
\hline & $\begin{array}{l}\text { Compared outcomes of patients who opted for immediate CPM versus those who did not. Study } \\
\text { group particularly interested in the impact of CPM during the immediate postdiagnostic period ( } 1 \\
\text { month after testing) and after the completion of adjuvant treatment ( } 12 \text { months after testing). }\end{array}$ \\
\hline \multirow[t]{2}{*}{ Tollin 2013} & Wrong intervention \\
\hline & As this was a web-based study, participants were able to complete all research instruments online. \\
\hline \multirow[t]{2}{*}{ Westin 2011} & Not all study participants were BRCA carriers. PROMs \\
\hline & $\begin{array}{l}\text { Questionnaire package to ascertain demographic and clinical information as well as quality of life } \\
\text { and beliefs regarding issues pertinent to women at high risk for developing breast and ovarian can- } \\
\text { cer. These questionnaires provided women with a variety of statements to describe their percep- } \\
\text { tions about screening, chemoprevention strategies, and risk-reducing surgery using Likert-based } \\
\text { scales. }\end{array}$ \\
\hline
\end{tabular}

CPM: contralateral prophylactic mastectomy PROMs: patient-reported outcome measures RRSO: risk-reducing salpingo-oophorectomy

\section{ADDITIONAL TABLES}

Table 1. Interpretation of domain levels and overall risk of bias judgement in ROBINS-I (Continued)

\begin{tabular}{|c|c|c|c|}
\hline Judgement & Within each domain & Across domains & Criterion \\
\hline $\begin{array}{l}\text { Low risk of } \\
\text { bias }\end{array}$ & $\begin{array}{l}\text { The study is comparable to a well-per- } \\
\text { formed randomised trial with regard to } \\
\text { this domain. }\end{array}$ & $\begin{array}{l}\text { The study is comparable to a } \\
\text { well-performed randomised trial. }\end{array}$ & $\begin{array}{l}\text { The study is judged to be at } \\
\text { low risk of bias for all domains. }\end{array}$ \\
\hline $\begin{array}{l}\text { Moderate } \\
\text { risk of bias }\end{array}$ & $\begin{array}{l}\text { The study is sound for a non-ran- } \\
\text { domised study with regard to } \\
\text { this domain but cannot be } \\
\text { considered comparable to a well-per- } \\
\text { formed randomised trial. }\end{array}$ & $\begin{array}{l}\text { The study provides sound evi- } \\
\text { dence } \\
\text { for a non-randomised study but } \\
\text { cannot be considered compara- } \\
\text { ble } \\
\text { to a well-performed randomised } \\
\text { trial. }\end{array}$ & $\begin{array}{l}\text { The study is judged to be at low or } \\
\text { moderate risk of bias for all do- } \\
\text { mains. }\end{array}$ \\
\hline $\begin{array}{l}\text { Serious risk } \\
\text { of bias }\end{array}$ & $\begin{array}{l}\text { The study has some important } \\
\text { problems in this domain. }\end{array}$ & $\begin{array}{l}\text { The study has some important } \\
\text { problems. }\end{array}$ & $\begin{array}{l}\text { The study is judged to be at serious } \\
\text { risk of bias in at least one domain, } \\
\text { but } \\
\text { not at critical risk of bias in any do- } \\
\text { main. }\end{array}$ \\
\hline $\begin{array}{l}\text { Critical risk } \\
\text { of bias }\end{array}$ & $\begin{array}{l}\text { The study is too problematic in this } \\
\text { domain to provide any useful }\end{array}$ & $\begin{array}{l}\text { The study is too problematic to } \\
\text { provide any useful evidence and }\end{array}$ & $\begin{array}{l}\text { The study is judged to be at critical } \\
\text { risk }\end{array}$ \\
\hline
\end{tabular}


Table 1. Interpretation of domain levels and overall risk of bias judgement in ROBINS-I (Continued)

evidence on the effects of

should not be used in any

intervention

synthesis.

\begin{tabular}{|c|c|c|c|}
\hline $\begin{array}{l}\text { No } \\
\text { information }\end{array}$ & $\begin{array}{l}\text { No information on which to base a } \\
\text { judgement about risk of bias for } \\
\text { this domain }\end{array}$ & $\begin{array}{l}\text { No information on which to base } \\
\text { a } \\
\text { judgement about risk of bias }\end{array}$ & $\begin{array}{l}\text { There is no clear indication that the } \\
\text { study is at serious or critical risk of } \\
\text { bias, and there is a lack of informa- } \\
\text { tion in }\end{array}$ \\
\hline & & & $\begin{array}{l}\text { one or more key domains of bias ( } a \\
\text { judgement is required for this). }\end{array}$ \\
\hline
\end{tabular}


Table 2. ROBINS- I ROB in NRS

\begin{tabular}{|c|c|c|c|c|c|c|c|}
\hline Study ID & Bias due to confounding & $\begin{array}{l}\text { Bias in se- } \\
\text { lection of } \\
\text { partici- } \\
\text { pants into } \\
\text { the study }\end{array}$ & $\begin{array}{l}\text { Bias in classifi- } \\
\text { cation of inter- } \\
\text { vention }\end{array}$ & $\begin{array}{l}\text { Bias due } \\
\text { to devia- } \\
\text { tions from } \\
\text { intended } \\
\text { interven- } \\
\text { tions }\end{array}$ & $\begin{array}{l}\text { Bias due to miss- } \\
\text { ing data }\end{array}$ & $\begin{array}{l}\text { Bias in measure- } \\
\text { ment of outcomes }\end{array}$ & $\begin{array}{l}\text { Bias in selec- } \\
\text { tion of the re- } \\
\text { ported result }\end{array}$ \\
\hline Bober 2015 & Moderate & $\begin{array}{l}\text { No } \\
\text { information }\end{array}$ & Low & $\begin{array}{l}\text { No } \\
\text { information }\end{array}$ & Low & Serious & Low \\
\hline $\begin{array}{l}\text { Support for } \\
\text { judgement }\end{array}$ & $\begin{array}{l}\text { "to meet study eligibility, women } \\
\text { needed to be<50, English speaking, } \\
\text { have undergone RRSO for ovarian can- } \\
\text { cer risk reduction prior to enrolment, } \\
\text { and endorse at least one distressing } \\
\text { symptom of sexual dysfunction on the } \\
\text { Sexual Problem Subscale of the Sexual } \\
\text { Function Questionnaire. } \\
\text { Exclusion criteria included history of } \\
\text { ovarian cancer, pelvic radiation, or } \\
\text { chemotherapy within the previous } \\
\text { year. Women } \\
\text { with a history of other cancers were } \\
\text { not excluded unless active treatment } \\
\text { had ended less than } 1 \text { year prior." }\end{array}$ & $\begin{array}{l}\text { There is no } \\
\text { matching } \\
\text { of a control } \\
\text { group. }\end{array}$ & $\begin{array}{l}\text { "trial was de- } \\
\text { signed to im- } \\
\text { prove subject } \\
\text { satisfaction with } \\
\text { sexual function, } \\
\text { increase knowl- } \\
\text { edge about sexu- } \\
\text { al function after } \\
\text { RRSO, increase } \\
\text { self-efficacy to } \\
\text { manage sexual } \\
\text { side effects, and } \\
\text { decrease psycho- } \\
\text { logical distress." }\end{array}$ & $\begin{array}{l}\text { There is no } \\
\text { comparator } \\
\text { group. }\end{array}$ & $\begin{array}{l}\text { "Forty-three } \\
\text { women enrolled in } \\
\text { the study and at- } \\
\text { tended one of the } \\
\text { scheduled groups } \\
\text { ( } 56 \% \text { of eligible } \\
\text { women screened). } \\
\text { Six women did not } \\
\text { return the postin- } \\
\text { tervention assess- } \\
\text { ment, despite re- } \\
\text { minders, yielding } \\
\text { an evaluable sam- } \\
\text { ple of } 37 \text { women } \\
\text { ( } 86 \% \text { completion } \\
\text { rate)." }\end{array}$ & $\begin{array}{l}\text { "The } 3.5 \text { hour group } \\
\text { session was struc- } \\
\text { tured around } 3 \text { mod- } \\
\text { ules facilitated by } \\
\text { the lead investiga- } \\
\text { tor... At approximate- } \\
\text { ly } 2 \text { and } 4 \text { weeks af- } \\
\text { ter the psychoedu- } \\
\text { cational session, tai- } \\
\text { lored, individual tele- } \\
\text { phone counselling } \\
\text { was provided to each } \\
\text { participant by the } \\
\text { lead investigator of } \\
\text { the study" }\end{array}$ & $\begin{array}{l}\text { "Differences } \\
\text { in baseline } \\
\text { and postin- } \\
\text { tervention } \\
\text { scores of the } \\
\text { FSFI, BSI-18, } \\
\text { sexual self-ef- } \\
\text { ficacy scale, } \\
\text { and sexual } \\
\text { knowledge } \\
\text { scale were ex- } \\
\text { amined us- } \\
\text { ing the paired } \\
\text { samples } t- \\
\text { test. Analy- } \\
\text { ses were re- } \\
\text { peated with } \\
\text { the nonpara- } \\
\text { metric Wilcox- } \\
\text { on signed } \\
\text { rank test. Re- } \\
\text { sults from } \\
\text { nonparamet- } \\
\text { ric analyses } \\
\text { were con- } \\
\text { sistent with } \\
t \text {-tests and } \\
\text { therefore not } \\
\text { included in } \\
\text { this report... } \\
\text { For outcome } \\
\text { measures } \\
\text { in which } \\
\text { changes were }\end{array}$ \\
\hline
\end{tabular}




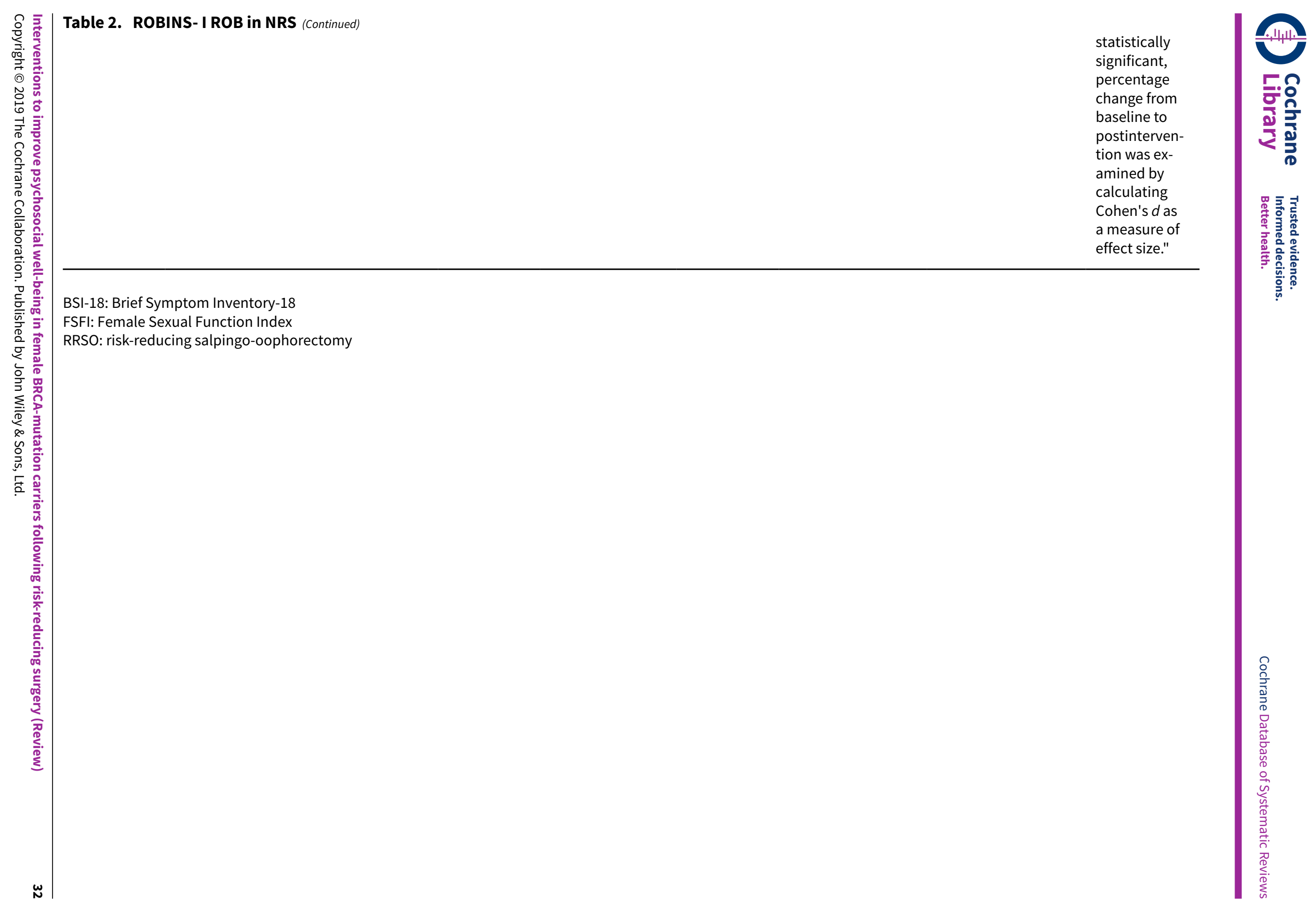


Table 3. Mindfulness-based stress reduction versus usual care

\begin{tabular}{|c|c|c|c|c|}
\hline & TO & T1 & T2 & T3 \\
\hline \multicolumn{5}{|c|}{ MENQOL total score } \\
\hline $\begin{array}{l}\text { Usual } \\
\text { care }\end{array}$ & 3.8 (3.4 to 4.3 ) & 3.8 (3.3 to 4.3$)$ & 3.7 (3.2 to 4.1$)$ & 3.9 (3.5 to 4.4$)$ \\
\hline MBSR & 4.1 (3.7 to 4.5$)$ & 3.5 (3.0 to 3.9$)$ & 3.7 (3.2 to 4.1$)$ & 3.6 (3.1 to 4.0$)$ \\
\hline $\mathbf{P}$ & - & 0.04 & 0.31 & 0.04 \\
\hline \multicolumn{5}{|c|}{ Vasomotor sub scale } \\
\hline $\begin{array}{l}\text { Usual } \\
\text { care }\end{array}$ & 4.2 (3.6 to 4.8$)$ & 4.1 (3.5 to 4.8$)$ & 4.2 (3.5 to 4.8$)$ & 4.3 (3.7 to 4.9$)$ \\
\hline MBSR & $4.5(4.0$ to 5.1$)$ & $3.5(2.9$ to 4.1$)$ & 3.8 (3.1 to 4.4$)$ & $3.6(3.0$ to 4.2$)$ \\
\hline $\mathbf{P}$ & - & 0.04 & 0.09 & 0.02 \\
\hline \multicolumn{5}{|c|}{ Psychosocial sub scale } \\
\hline $\begin{array}{l}\text { Usual } \\
\text { care }\end{array}$ & 3.7 (3.2 to 4.2$)$ & 3.6 (3.0 to 4.1$)$ & 3.6 (3.0 to 4.2 ) & 3.8 (3.3 to 4.4$)$ \\
\hline MBSR & 3.8 (3.3 to 4.3$)$ & $3.4(2.8$ to 3.9$)$ & 3.6 (3.0 to 4.2$)$ & 3.7 (3.1 to 4.3 ) \\
\hline $\mathbf{P}$ & - & 0.31 & 0.95 & 0.50 \\
\hline \multicolumn{5}{|c|}{ Physical sub scale } \\
\hline $\begin{array}{l}\text { Usual } \\
\text { care }\end{array}$ & 3.5 (3.1 to 3.9$)$ & 3.6 (3.2 to 4.0$)$ & 3.5 (3.0 to 3.9$)$ & 3.893 .3 to 4.2$)$ \\
\hline MBSR & 3.5 (3.2 to 3.9$)$ & $3.0(2.6$ to 3.4$)$ & $3.3(2.9$ to 3.7$)$ & $3.2(2.7$ to 3.6$)$ \\
\hline $\mathbf{P}$ & - & 0.01 & 0.32 & 0.03 \\
\hline \multicolumn{5}{|c|}{ Sexual sub scale } \\
\hline $\begin{array}{l}\text { Usual } \\
\text { care }\end{array}$ & 4.0 (3.1 to 4.8$)$ & 3.9 (3.0 to 4.7$)$ & 3.5 (2.7 to 4.3$)$ & 3.7 (2.9 to 4.4$)$ \\
\hline MBSR & $4.4(3.6$ to 5.2$)$ & 4.1 (3.3 to 4.9$)$ & $4.2(3.4$ to 5.0$)$ & $4.0(3.2$ to 4.8$)$ \\
\hline $\mathbf{P}$ & - & 0.66 & 0.39 & 0.77 \\
\hline
\end{tabular}

MBSR: mindfulness-based stress reduction

MENQOL: Menopause-Specific Quality of Life questionnaire 


\begin{tabular}{|c|c|c|c|c|c|c|c|}
\hline$(n=37)$ & Baseline & & Postin & & Chang & & \\
\hline Measure & M & SD & $M$ & SD & $M$ & SD & $95 \% \mathrm{Cl}$ \\
\hline FSFI total $(n=34)$ & 15.63 & 10.23 & 19.54 & 9.47 & 3.91 & 9.12 & 0.84 to 6.98 \\
\hline Desire & 1.98 & 1.14 & 2.42 & 1.09 & 0.44 & 0.83 & 0.17 to 0.71 \\
\hline Arousal & 2.69 & 1.98 & 3.68 & 1.84 & 0.98 & 1.86 & 0.38 to 1.58 \\
\hline Lubrication $(n=36)$ & 2.38 & 2.09 & 2.97 & 2.05 & 0.58 & 2.03 & -0.08 to 1.24 \\
\hline Orgasm & 2.86 & 2.39 & 3.59 & 2.23 & 0.73 & 2.32 & -0.02 to 1.48 \\
\hline Satisfaction & 2.70 & 1.73 & 3.23 & 1.67 & 0.53 & 1.40 & 0.08 to 0.98 \\
\hline Pain & 2.35 & 2.36 & 3.28 & 2.45 & 0.93 & 2.28 & 0.20 to 1.66 \\
\hline BSI-18 GSI & 50.89 & 7.99 & 46.97 & 7.52 & 3.92 & 5.94 & 2.01 to 5.83 \\
\hline Somatisation & 50.89 & 8.22 & 48.14 & 8.20 & 2.76 & 7.35 & 0.39 to 5.13 \\
\hline Depression & 49.76 & 8.48 & 47.54 & 7.31 & 2.22 & 7.72 & 0.27 to 4.71 \\
\hline Anxiety & 51.16 & 7.85 & 47.41 & 6.36 & 3.76 & 5.89 & 1.86 to 5.66 \\
\hline Sexual self-efficacy scale & 63.54 & 24.98 & 75.68 & 18.38 & 12.14 & 20.56 & 5.52 to 18.76 \\
\hline Sexual knowledge scale & 7.97 & 1.63 & 9.06 & 1.17 & 1.08 & 1.50 & 0.6 to 1.56 \\
\hline Change scores are expressed in abs & ute value. & & & & & & \\
\hline $\begin{array}{l}\text { BSI-18: Brief Symptom Inventory-18 } \\
\text { CI: confidence interval } \\
\text { FSFI: Female Sexual Function Index } \\
\text { GSI: Global Severity Index } \\
\text { SD: standard deviation }\end{array}$ & & & & & & & \\
\hline
\end{tabular}




\section{APPEN DICES}

\section{Appendix 1. CENTRAL search strategy}

\#1. MeSH descriptor: [Genes, BRCA1] this term only \#2. MeSH descriptor: [BRCA1 Protein] this term only \#3. MeSH descriptor: [Genes, BRCA2] this term only \#4. MeSH descriptor: [BRCA2 Protein] this term only \#5. BRCA* $^{*}$ or brca*

\#6. $\left(\right.$ BRCA $^{\star}$ or brca*) near/5 (carrier ${ }^{\star}$ or tumor ${ }^{\star}$ or tumour ${ }^{\star}$ or gene ${ }^{\star}$ or suppress ${ }^{\star}$ or protein ${ }^{\star}$ or mutat or alter $^{\star}$ or damage $^{\star}$ or inherit $^{\star}$ or heredit*)

$\# 7$. \#1 or \#2 or \#3 or \#4 or \#5 or \#6

\#8. MeSH descriptor: [Prophylactic Surgical Procedures] this term only

\#9. MeSH descriptor: [Mastectomy] explode all trees

\#10. MeSH descriptor: [Ovariectomy] this term only

$\# 11$. Any MeSH descriptor with qualifier(s): [Surgery - SU]

\#12. (risk reduc* or prophylactic) near/5 (surg* or mastectom* or RRM or ovar* or RRBSO or BSO or bilateral salpingo-oophorectom* or oophorectomy* or interven ${ }^{\star}$ )

$\# 13$. \#8 or \#9 or \#10 or \#11 or \#12

$\# 14$. \#7 and \#13

\section{Appendix 2. MEDLINE search strategy}

1. Genes, BRCA1/

2. BRCA1 Protein/

3. Genes, BRCA2/

4. BRCA2 Protein/

5. (BRCA* or brca* or hereditary breast-ovarian cancer syndrome or hereditary breast ovarian cancer syndrome or HBOC).mp.

6. ((BRCA* or brca*) adj5 (carrier* or tumor ${ }^{\star}$ or tumour ${ }^{\star}$ or gene ${ }^{\star}$ or suppress ${ }^{\star}$ or protein ${ }^{\star}$ or mutat ${ }^{\star}$ or alter or damage $^{\star}$ or inherit $^{\star}$ or heredit $\left.\left.{ }^{\star}\right)\right) \cdot \mathrm{mp}$.

7. 1 or 2 or 3 or 4 or 5 or 6

8. Prophylactic Surgical Procedures/

9. exp Mastectomy/

10. Ovariectomy/

11. surgery.fs.

12. ((risk reduc ${ }^{\star}$ or prophyla*) adj5 (surg* or procedur ${ }^{\star}$ or tech ${ }^{\star}$ or mastectom ${ }^{\star}$ or RRM or ovar ${ }^{\star}$ or RRBSO or BSO or bilateral salpingo-oophorectom* or oophorectomy* or interven $\left.\left.{ }^{\star}\right)\right) . m p$.

13. 8 or 9 or 10 or 11 or 12

14. 7 and 13

15. randomized controlled trial.pt.

16. controlled clinical trial.pt.

17. randomized.ab.

18. placebo.ab.

19. drug therapy.fs.

20. randomly.ab.

21. trial.ti.

22. groups.ab.

23. exp cohort studies/

24. exp case-control studies/

25. (cohort ${ }^{\star}$ or prospective ${ }^{\star}$ or retrospective ${ }^{\star}$ or (case ${ }^{\star}$ and (control ${ }^{\star}$ or series))).mp.

26.15 or 16 or 17 or 18 or 19 or 20 or 21 or 22 or 23 or 24 or 25

27. (animals not (humans and animals)).sh.

28. 26 not 27

29. 14 and 28

Key

[mp = title, abstract, original title, name of substance word, subject heading word, keyword heading word, protocol supplementary concept word, rare disease supplementary concept word, unique identifier]

\section{Appendix 3. Embase search strategy}

1. tumor suppressor gene/

2. BRCA1 protein/

Interventions to improve psychosocial well-being in female BRCA-mutation carriers following risk-reducing surgery (Review)

Copyright (c) 2019 The Cochrane Collaboration. Published by John Wiley \& Sons, Ltd. 
3. BRCA2 protein/

4. $\left(\mathrm{BRCA}^{\star}\right.$ or $\left.\mathrm{brca}^{\star}\right) \cdot \mathrm{mp}$.

5. ((BRCA* or brca*) adj5 (carrier ${ }^{\star}$ or tumor ${ }^{\star}$ or tumour ${ }^{\star}$ or gene $e^{\star}$ or suppress ${ }^{\star}$ or protein ${ }^{\star}$ or mutat ${ }^{\star}$ or alter or damage $^{\star}$ or inherit ${ }^{\star}$ or heredit*)).mp.

6.1 or 2 or 3 or 4 or 5

7. prophylactic surgical procedure/

8. exp mastectomy/

9. ovariectomy/

10. surgery.fs.

11. ((risk reduc ${ }^{\star}$ or prophylactic) adj5 (surg* or mastectom* or RRM or ovar* or RRBSO or BSO or bilateral salpingo-oophorectom* or oophorectomy* or interven $\left.{ }^{\star}\right)$ ).mp.

12. 7 or 8 or 9 or 10 or 11

13.6 and 12

14. exp controlled clinical trial/

15. randomized.ab.

16. randomly.ab.

17. trial.ab.

18. groups.ab.

19. exp cohort analysis/

20. cohort*.mp.

21. exp retrospective study/

22. exp prospective study/

23. (case ${ }^{\star}$ and series).mp.

24. 14 or 15 or 16 or 17 or 18 or 19 or 20 or 21 or 22 or 23

25. 13 and 24

\section{Key}

$[\mathrm{mp}=$ title, abstract, original title, name of substance word, subject heading word, keyword heading word, protocol supplementary concept word, rare disease supplementary concept word, unique identifier]

\section{Appendix 4. CINAHL search strategy}

S25 S9 AND S23 Limiters - Published Date: 19950101-20180131; Publication Type: Clinical Trial, Meta Analysis, Meta Synthesis, Randomized Controlled Trial, Research, Systematic Review

\section{S24 S9 AND S23}

S23 S10 OR S11 OR S12 OR S13 OR S14 OR S15 OR S16 OR S17 OR S18 OR S19 OR S20 OR S21 OR S22

S22 "interven"

S21 (MH "Surgery, Operative")

S20 "ovariectomy"

S19 (MH "Oophorectomy") OR "oophorectomy"

S18 "bilateral salpingo-oophorectom*"

S17 "BSO"

S16 "RRBSO"

S15 "OVAR"

S14 "RRM"

S13 "mastectom*"

S12 (MH "Mastectomy") OR (MH "Prophylactic Mastectomy")

S11 "risk reducing surg*"

S10 "prophylactic surgical procedures"

S9 S1 OR S2 OR S4 OR S5 OR S7 OR S8

S8 "BRCA*"

$\mathrm{S} 7$ "brca*"

S6 "(BRCA* or brca*) N5 (carrier* or tumor ${ }^{\star}$ or tumour ${ }^{\star}$ or gene* or supress ${ }^{\star}$ or protein ${ }^{\star}$ or mutat ${ }^{\star}$ or alter ${ }^{\star}$ or damage or inherit $^{\star}$ or heredit*))"

S5 "BRCA* OR brca*"

S4 "brca2"

S3 "brca protein"

S2 "brca1"

S1 (MH "Genes, BRCA") 


\title{
Appendix 5. PsycINFO search strategy
}

1 PROPHYLACTIC SURGICAL PROCEDURES.mp. [mp = title,abstract, heading word, table of contents, key concepts, original title,tests \& measures]

2 exp MASTECTOMY/

3 exp OVARIECTOMY/

4 exp SURGERY/

5 risk reduc* surg*.mp.[mp = title,abstract, heading word, table of contents, key concepts, original title,tests \& measures]

6 mastectom ${ }^{\star} \mathrm{mp}$. [ $\mathrm{mp}=$ title,abstract, heading word, table of contents, key concepts, original title,tests \& measures]

7 RRM.mp. [mp = title,abstract, heading word, table of contents, key concepts,original title,tests \& measures]

$8 \mathrm{OVAR}^{\star} . \mathrm{mp}$. [mp = title,abstract, heading word, table of contents, key concepts,original title,tests \& measures]

9 RRBSO.mp. [mp = title,abstract, heading word, table of contents, key concepts, original title,tests \& measures]

10 BSO.mp. [mp = title,abstract, heading word, table of contents, key concepts, original title,tests \& measures]

11 bilateral salpingo-oophorectom ${ }^{\star} . \mathrm{mp}$. [mp = title, abstract, heading word, table of contents, key concepts, original title,tests \& measures]

12 oophorectomy ${ }^{\star} . \mathrm{mp}$. [mp = title, abstract, heading word, table of contents, key concepts, original title,tests \& measures]

131 or 2 or 3 or 4 or 5 or 6 or 7 or 8 or 9 or 10 or 11 or 12

14 brca.mp.

15 brca1.mp.

$16 \mathrm{brca}^{*} . \mathrm{mp}$.

17 brca2.mp.

1814 or 15 or 16 or 17

1913 and 18

20 limit 19 to $y r=$ "195-Current"

1 from 20 keep 1-254

\section{Appendix 6. Web of Science}

\author{
\# 3 \#2 AND \#1 \\ Indexes = SCI-EXPANDED, SSCI, A\&HCI, CPCI-S, CPCI-SSH, ESCI Timespan = All years \\ \#2 TOPIC: (prophylactic surgical procedures) OR TOPIC: (mastectom ${ }^{\star}$ ) OR TOPIC: (ovariectomy) OR TOPIC: (surgery) \\ OR TOPIC: (RRM) OR TOPIC: (RRBSO) OR TOPIC: (BSO) OR TOPIC: (BILATERAL SALPINGO-OOPHORECTOM*) OR TOPIC: \\ (oophorectomy*) \\ Indexes = SCI-EXPANDED, SSCI, A\&HCI, CPCI-S, CPCI-SSH, ESCI Timespan = All years \\ \#1 TOPIC: (brca*) \\ Indexes $=S C I$-EXPANDED, SSCI, A\&HCI, CPCI-S, CPCI-SSH, ESCI Timespan = All years
}

\section{Appendix 7. Data extraction form}

\section{Review title or ID}

- Study ID (surname of first author and year first full report of study was published e.g. Smith 2001).

- Report IDs of other reports of this study (e.g. duplicate publications, follow-up studies).

- Notes.

\section{General information}

- Date form completed (dd/mm/yyyy).

- Name/ID of person extracting data.

- Report title (title of paper/ abstract/ report that data are extracted from).

- Report ID (if there are multiple reports of this study).

- Country of origin.

- Publication type (e.g. full report, abstract, letter).

- Study funding source (including role of funders).

- Possible conflicts of interest (for study authors).

- Notes.

\section{Eligibility}

\section{Study characteristics}

- Review inclusion criteria (insert inclusion criteria for each characteristic as defined in the protocol): Yes/No/Unclear.

- Location in text (page and paragraph/figure/table).

- Type of study. 
- Randomised trial/non-randomised trial.

- Other design (specify).

- Participants.

- Types of intervention.

- Types of outcome measures.

- Decision.

- Reason for exclusion.

- Notes.

\section{Do not proceed if study excluded from review}

\section{Population and setting}

- Description.

- Include comparative information for each group (i.e. intervention and controls) if available.

- Location in text (page and paragraph/figure/table).

- Population description (from which study participants are drawn).

- Setting (including location and social context).

- Inclusion criteria.

- Exclusion criteria.

- Method(s) of recruitment of participants.

- Notes.

\section{Methods}

- Descriptions as stated in report/paper.

- Location in text (page and paragraph/figure/table).

- Study aim.

- Design (e.g. parallel, crossover, non-RCT).

- Start date.

- End date.

- Duration of participation (from recruitment to last follow-up).

- Notes.

\section{'Risk of bias' assessment}

See Chapter 8 of the Cochrane Handbook for Systematic Reviews of Interventions (Higgins 2011b). Additional domains may be required for non-randomised studies.

\section{Domain}

- Risk of bias: low/high/unclear:

* support for judgement;

* location in text (page and paragraph/figure/table);

* random sequence generation (selection bias).

- Allocation concealment (selection bias).

- Blinding of participants and personnel (performance bias):

* outcome group: all/(if required);

* outcome group.

- Blinding of outcome assessment (detection bias):

* outcome group: all/(if required);

* outcome group.

- Incomplete outcome data (attrition bias).

- Selective outcome reporting? (reporting bias).

- Other bias.

- Notes. 


\section{Participants}

Provide overall data and, if available, comparative data for each intervention or comparison group.

- Description as stated in report/paper.

- Location in text (page and paragraph/figure/table).

- Total number randomised (or total population at start of study for NRCTs).

- Clusters (if applicable, number, type, number people per cluster).

- Baseline imbalances.

- Withdrawals and exclusions (if not provided below by outcome).

- Age.

- Sex.

- Race/ethnicity.

- Subgroups measured.

- Cancer (Y/N).

- Type of cancer.

- Risk-reducing mastectomy.

- RRSO.

- BRCA1 or BRCA2.

- Subgroups reported.

- Notes.

\section{Intervention groups}

(Copy and paste table for each intervention and comparison group)

- Intervention Group 1.

- Description as stated in report/paper.

- Location in text (page and paragraph/figure/table).

- Group name.

- Number randomised to group (specify whether number of people or clusters).

- Description (include sufficient detail for replication, e.g. content, dose, components; if it is a natural experiment, describe the preintervention).

- Duration of treatment period.

- Timing (e.g. frequency, duration of each episode).

- Delivery (e.g. mechanism, medium, intensity, fidelity).

- Providers (e.g. number, profession, training, ethnicity etc. if relevant).

- Co-interventions.

- Notes.

\section{Outcomes}

(Copy and paste table for each outcome)

- Outcome 1.

- Description as stated in report/paper.

- Location in text (page and paragraph/figure/table).

- Outcome name.

- Time points measured (specify whether from start or end of intervention).

- Time points reported.

- Outcome definition (with diagnostic criteria if relevant and note whether the outcome is desirable or undesirable if this is not obvious).

- Person measuring/reporting.

- Unit of measurement (if relevant).

- Scales: upper and lower limits (indicate whether high or low score is good).

- Is outcome/tool validated? Yes/No/Unclear.

- Imputation of missing data (e.g. assumptions made for ITT analysis). 
- Notes.

\section{Results}

(Copy and paste the appropriate table for each outcome, including additional tables for each time point and subgroup as required)

\section{For randomised or non-randomised trial: dichotomous outcome}

- Description as stated in report/paper.

- Location in text (page and paragraph/figure/table).

- Comparison.

- Outcome.

- Subgroup.

- Time point (specify whether from start or end of intervention).

- Note whether: post-intervention or change from baseline.

- Adjusted.

- Unadjusted.

- Intervention.

- Comparison.

- Number of events.

- Number of participants.

- Number of events.

- Number of participants.

\section{Baseline data}

- Intervention.

- Comparison

- Number of events.

- Number participants.

- Number of events.

- Number of participants.

- Number of missing participants and reasons.

- Number of participants moved from other group and reasons.

- Any other results reported.

- Unit of analysis (e.g. by individuals, health professional, practice, hospital, community).

- Statistical methods used and appropriateness of these methods (e.g. adjustment for correlation).

- Notes. 


\section{For randomised or non-randomised trial : continuous outcome}

- Description as stated in report/paper:

* location in text (page and paragraph/figure/table);

* comparison;

* outcome;

* subgroup;

* time point (specify whether from start or end of intervention);

* post-intervention or change from baseline;

* results;

$\square$ note whether: post-intervention or change from baseline;

$\square$ and whether adjusted or unadjusted;

$\square$ intervention;

$\square$ comparison;

$\square$ mean;

$\square$ SD (or other variance);

$\square$ number of participants;

$\square$ mean;

SD (or other variance);

number of participants.

\section{Baseline data}

- Intervention.

- Comparison.

- Mean.

- SD (or other variance).

- Number of participants.

- Mean.

- SD (or other variance).

- Number of participants.

- Number of missing participants and reasons.

- Number of participants moved from other group and reasons.

- Any other results reported.

- Unit of analysis (e.g. by individuals, health professional, practice, hospital, community).

- Statistical methods used and appropriateness of these methods (e.g. adjustment for correlation).

- Notes.

\section{For randomised or non-randomised trial: other outcome}

- Description as stated in report/paper.

- Location in text (page and paragraph/figure/table).

- Comparison.

- Outcome.

- Subgroup.

- Time point (specify whether from start or end of intervention).

- Type of outcome. 
- Results:

* intervention result;

* SD (or other variance);

* control result;

* SD (or other variance);

* overall results;

* SE (or other variance);

* number of participants;

* intervention;

* control;

* number of missing participants and reasons;

* number of participants moved from other group and reasons;

* any other results reported;

* unit of analysis (e.g. by individuals, health professional, practice, hospital, community);

* statistical methods used and appropriateness of these methods;

- Notes:

\section{For controlled before-after study}

- Description as stated in report/paper.

- Location in text (page and paragraph/figure/table).

- Comparison.

- Outcome.

- Subgroup.

- Timepoint (specify whether from start or end of intervention).

- Post-intervention or change from baseline.

- Results:

* intervention result;

* SD (or other variance);

* control result;

* SD (or other variance);

* overall results;

* SE (or other variance);

* No. participants;

* intervention;

* control;

* number of missing participants and reasons;

* number of participants moved from other group and reasons;

* any other results reported;

* unit of analysis (individuals, cluster/ groups or body parts);

* statistical methods used and appropriateness of these methods.

- Notes.

For interrupted time series or repeated measures study

- Description as stated in report/paper.

- Location in text (page and paragraph/figure/table).

- Comparison.

- Outcome.

- Subgroup.

- Length of time points measured (e.g. days, months).

- Total period measured.

- Number of participants measured.

- Number of missing participants and reasons.

- Number of time points measured. 
- Pre-intervention.

- Post-intervention.

- Mean value (with variance measure).

- Difference in means (post- and pre-intervention).

- Percent relative change.

- Result reported by authors (with variance measure).

- Unit of analysis (individuals or cluster/groups).

- Statistical methods used and appropriateness of these methods.

- Notes.

\section{Applicability}

- Does the study directly address the review question? (any issues of partial or indirect applicability): Yes/No/Unclear.

- Notes.

\section{Other information}

- Description as stated in report/paper.

- Location in text (page and paragraph/figure/table).

- Key conclusions of study authors.

- References to other relevant studies.

- Correspondence required for further study information (what and from whom).

- Further study information requested (from whom, what and when).

- Correspondence received (from whom, what and when).

- Notes

\section{CONTRIBUTIONS OF AUTHORS}

All authors read and approved the final review draft.

Lisa Jeffers: conceptualising the topic for the review, drafting the manuscript Joanne Reid: reviewing and editing the manuscript Donna Fitzsimons: reviewing and editing the manuscript Patrick J Morrison: reviewing and editing the manuscript Martin Dempster: reviewing and editing the manuscript

\section{DECLARATIONS OF INTEREST}

Lisa Jeffers: I have already acknowledged the Cochrane Fellowship in my protocol. Joanne Reid: none known Donna Fitzsimons: none known Patrick J Morrison: none known Martin Dempster: none known

\section{SOURCES OF SUPPORT}

\section{Internal sources}

- No internal sources of support, Other.

\section{External sources}

- Health and Social Care R\&D Division of the Public Health Agency (Northern Ireland), UK.

Funded Lisa Jeffers to undertake this review as part of its Cochrane Fellowship Ireland scheme

\section{DIFFERENCES BETWEEN PROTOCOL AND REVIEW}

\section{Assessment of heterogeneity}

If in a future update additional studies are identified, we expect some heterogeneity due to clinical and methodological diversity. We will therefore assess heterogeneity between studies by visual inspection of forest plots; by estimation of the percentage heterogeneity 
between trials that cannot be ascribed to sampling error ( $I^{2}$ statistic) (Higgins 2003); by a formal statistical test of the significance of the heterogeneity (Chi ${ }^{2}$ test) (Deeks 2001); and, if possible, by subgroup analyses. If there is no evidence of heterogeneity, we will use a fixedeffect model, which assumes a common underlying effect behind every trial. If there is evidence of substantial heterogeneity, we will investigate and report the possible reasons for this. If we suspect marked heterogeneity, we will not combine estimates. All potential causes of such heterogeneity will be explored through subgroup and sensitivity analysis. We will use a random-effects model if metaanalysis is appropriate; we will assume each trial to be measuring a different, true effect. Whilst it is acknowledged that a random-effects model is more susceptible to publication bias, we will incorporate methods to formally test publication bias into the analysis as outlined below.

\section{Assessment of reporting biases}

In a future update, if appropriate (i.e. if the review includes more than 10 randomised controlled trials (RCTs)), we will examine funnel plots corresponding to meta-analysis of the primary outcome to assess the potential for small-study effects such as publication bias. Additionally, we will explore possible sources of asymmetry in funnel plot, such as selective outcome reporting, poor methodological quality leading to spuriously inflated effects in smaller studies, true heterogeneity, artefactual and chance as outlined by Egger 1997. If these plots suggest that treatment effects may not be sampled from a symmetric distribution, as assumed by the random-effects model, we will perform further meta-analysis using a fixed-effect model. If the review includes fewer than 10 RCTs, then we will use a qualitative assessment of reporting biases, whereby the authors will review and summarise the evidence from the RCTs.

\section{Data synthesis}

If in a future update we include both RCTs and non-randomised studies, and if sufficient, clinically similar studies are available, we will pool their results in meta-analyses using Review Manager 5 (RevMan 2014). We will use adjusted summary statistics if available; otherwise we will use unadjusted results. Where more than one adjusted effect is reported in a paper, we will use the estimate that is identified as the primary adjusted effect by the study authors.

We will use random-effects employing inverse-variance weighting for any meta-analysis.

For continuous outcomes, we will pool the mean differences between the treatment arms at the end of follow-up if all trials measured the outcome on the same scale; otherwise we will pool the standardised mean difference. For any dichotomous outcomes, we will calculate the risk ratio for each study and then pool these. The final discussion will include a narrative synthesis of the findings of each study design.

\section{Subgroup analysis and investigation of heterogeneity}

We will not perform post hoc subgroup analysis. Where appropriate, we will undertake subgroup analysis, potentially grouping the trials by the following.

- Type of treatment regimen (psychological, psychoeducational, psychosexual intervention)

- Duration of treatment (short term less than one month, longer term more than three months)

- Cancer diagnosis (affected women) or no cancer (healthy at-risk women)

- Type of risk-reducing surgery (mastectomy or risk-reducing salpingo-oophorectomy)

\section{Sensitivity analysis}

In a future update, where possible, we will perform the following sensitivity analyses.

- Exclusion of studies that are at high risk of bias

- Using unadjusted results

If possible, we will conduct the analyses on an intention-to-treat basis. If this is not possible, we will use available-case analysis. The sensitivity analysis will consider how the results would have differed for assumed means or event rates for missing data. 